(C) 2018 Universidad Nacional Autónoma de México, Facultad de Estudios Superiores Zaragoza.

Este es un artículo Open Access bajo la licencia CC BY-NC-ND (http://creativecommons.org/licenses/by-nc-nd/4.0/).

TIP Revista Especializada en Ciencias Químico-Biológicas, 21(Supl. 2): 85-101, 2018.

DOI: 10.22201/fesz.23958723e.2018.0.159

\title{
DOMESTICACIÓN, DIVERSIDAD Y RECURSOS GENÉTICOS Y GeNómicos de MÉXICO: El CASO de las Calabazas
}

\author{
Luis E. Eguiarte ${ }^{1 * a}$, Helena S. Hernández-Rosales', \\ Josué Barrera-Redondo', Gabriela Castellanos-Morales ${ }^{1,2,3}$, \\ Leslie M. Paredes-Torres', Guillermo Sánchez-de la Vega', \\ Karen Y. Ruiz-Mondragón', Alejandra Vázquez-Lobo ${ }^{4}$, \\ Salvador Montes-Hernández ${ }^{5}$, Erika Aguirre-Planter ${ }^{1}$, \\ Valeria Souza ${ }^{1}$ y Rafael Lira ${ }^{2 * b}$ \\ ${ }^{1}$ Laboratorio de Evolución Molecular y Experimental, Departamento de Ecología Evolutiva, \\ Instituto de Ecología, Universidad Nacional Autónoma de México. Circuito Exterior s/n Anexo al \\ Jardín Botánico, Ciudad de México, 04510, México. ${ }^{2}$ UBIPRO, Facultad de Estudios Superiores \\ Iztacala, Universidad Nacional Autónoma de México. ${ }^{3}$ Departamento de Conservación de la \\ Biodiversidad, El Colegio de la Frontera Sur, Villahermosa. Villahermosa, Tabasco, México. ${ }^{4}$ Centro \\ de Investigaciones en Biodiversidad y Conservación, Universidad Nacional Autónoma del Estado de \\ Morelos, Cuernavaca, Morelos, México. ${ }^{5}$ Instituto Nacional de Investigaciones Forestales, Agrícolas y \\ Pecuarias (INIFAP), Celaya, Guanajuato, México. Emails: ${ }^{\mathrm{f}}$ runs@unam.mx, ${ }^{b}$ rlira@unam.mx
}

\section{RESUMEN}

La domesticación de plantas y animales permite estudiar diferentes procesos evolutivos, como la selección, adaptación y especiación. En este artículo se describen avances recientes en el estudio de las calabazas, las cuales constituyen el género Cucurbita (Cucurbitaceae) siendo un grupo de plantas herbáceas americanas que incluyen entre 12 y 15 especies. Cucurbita ha tenido seis eventos de domesticación, de los cuales cuatro sucedieron en México. Este es un género relativamente reciente, que surgió en Norte América hace 16 millones de años y sus especies cultivadas mantienen una alta variación genética; Cucurbita pepo es la especie que presenta mayor variación genética,variación asociada a dos domesticaciones independientes, una en el norte de México, y otra en el Sureste de los Estados Unidos. En otra especie, Cucurbita argyrosperma, sus poblaciones de la Península de Yucatán, representan una poza genética diferenciada del resto de la especie. El estudio del genoma de C. argyrosperma y taxa cercanos ha revelado las regiones de su genoma asociadas a la domesticación. Las poblaciones de las especies de este género representan una fuente de importantes recursos genéticos frente al cambio climático y constituyen un buen sistema para el estudio de la domesticación y de diferentes procesos evolutivos.

Palabras Clave: Cloroplasto, Cucurbita, filogenia, genética de poblaciones, genómica.

\section{Domestication, diversity, genetic and genomic resources of Mexico: The case of pumpkins}

\begin{abstract}
The domestication of plants and animals allows the study of different evolutionary processes, including selection, adaptation and speciation. Here we describe recent advances in the study of pumpkins and squashes, which constitute the genus Cucurbita (Cucurbitaceae), being a group of herbaceous plants from the Americas that include between 12 and 15 species. Cucurbita has had six domestication events, four of them occurred in Mexico. This is a relatively recent genus that originated in North America 16 million years ago and its cultivated species maintain high levels of genetic variation. Cucurbita pepo is the species with the highest genetic diversity, diversity associated to two independent domestications, one in Northern Mexico and the other in Southern United States. In another species, Cucurbita argyrosperma, the populations from Yucatan Peninsula represents a genetic pool differentiated from the rest of the species. The study of the genome of $\mathrm{C}$. argyrosperma and related taxa has revealed the regions of its genome associated with domestication. The populations of the species of this genus represent a source of important genetic resources in the face of climate change and constitute a good system for the study of domestication and of different evolutionary processes.
\end{abstract}

Key words: Chloroplast, Cucurbita, genomics, phylogeny, population genetics.

Nota: Artículo recibido el 26 de marzo del 2018 y aceptado

el 23 de octubre del 2018. 


\section{LA DOMESTICACIÓN COMO UN PROBLEMA EVOLUTIVO}

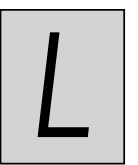
a domesticación es un proceso por el cual los humanos llegan a controlar la reproducción y/o la sobrevivencia de otro organismo (animal, planta, hongo o bacteria), para así aprovechar con más eficiencia algún recurso que produzca ese organismo (Solbrig \& Solbrig, 1994; Zeder, 2015). Durante la domesticación se seleccionan diferentes características útiles para el humano (Darwin, 1859; Solbrig \& Solbrig, 1994; Zizumbo -Villarreal \& Colunga-GarcíaMarín, 2010).

La domesticación ha fascinado a los naturalistas y biólogos por mucho tiempo. Así, hay diferentes trabajos clásicos sobre la domesticación de plantas y animales, entre los que destacan los estudios de Charles Darwin (1809-1882). Si recuerda el lector, sus ejemplos de selección en el Origen de las Especies (1859) se refieren a casos de selección artificial por los humanos y a partir de ellos deduce y ejemplifica que un proceso similar debe ocurrir en especies silvestres, que es la selección natural.

Otro científico importante en los primeros estudios sobre domesticación fue Alphonse Pyrame de Candolle (1806-1893), un botánico suizo que fue una de las primeras personas en pensar seriamente de dónde venían las plantas cultivadas en su obra Origine des plantes cultivées (1883). Candolle intenta descubrir los parientes silvestres de las plantas cultivadas y su distribución geográfica, para luego explicar los mecanismos de cómo han llegado a diferentes lugares y su variación geográfica. Ya durante el siglo XX, el famoso científico soviético Nikolai Vavilov (1887- 1943) fue el primero en describir a México y Mesoamérica como centros activos de domesticación de plantas y realizó amplias colectas de germoplasma e importantes estudios en muchas partes del mundo, incluyendo a una buena parte de México (Jardón-Barbolla, 2015).

A partir de estos estudios seminales, se han desarrollado un creciente número de estudios sobre el proceso y la genética de la domesticación. Se ha encontrado que para el caso de las plantas lo que usualmente se selecciona es la cantidad y la calidad de los frutos y semillas que producen, mismos que son la principal fuente alimenticia de los seres humanos (Solbrig \& Solbrig, 1994). Pero hay otras características que también se seleccionan en estas plantas para facilitar su manejo; por ejemplo, se ha seleccionado que no se liberen las semillas, como en el maíz, que quedan unidas al olote, o permanecen en la vaina, como en los frijoles, para que el agricultor no las pierda. También se han desarrollado variedades donde se eliminan pelos irritantes y compuestos tóxicos en las hojas o frutos, adaptaciones que les ayudan en las condiciones silvestres a no ser consumidas por herbívoros, pero que perderlas las hace más fáciles de manejar por los campesinos, o se vuelven más sabrosas y nutritivas, al no ser tóxicas (Solbrig \& Solbrig, 1994; Purugganan \& Fuller, 2009; Zizumbo -Villarreal \& ColungaGarcíaMarín, 2010; Meyer \& Purugganan, 2013). Así, se llega a un punto en el que la planta (o el organismo domesticado) ya no puede reproducirse sin ayuda del humano. En este momento se considera que un organismo esta totalmente domesticado, como lo veremos después. Las plantas domesticadas también cambian su fenología (crecen más rápido o muestran una mayor plasticidad en sus fechas de germinación que sus contrapartes silvestres) sus semillas usualmente son más grandes, germinan más fácil y uniformemente (no presentan latencia, por ejemplo) facilitando su manejo y consumo. (Solbrig \& Solbrig, 1994; Purugganan \& Fuller, 2009; Zizumbo -Villarreal \& ColungaGarcía Marín, 2010; Meyer \& Purugganan, 2013; Gaut, 2015; Gaut et al., 2015).

En animales el proceso de domesticación es más complejo y variable que en las plantas, depende del uso del animal, pero generalmente se selecciona que los animales sean más fáciles de manejar, menos feroces o peligrosos (Francis, 2015). En algunos animales lo que se busca al seleccionarlos es que crezcan rápido y que mejore la calidad de su carne; en otros animales, como en las vacas o cabras, lo que se selecciona es la cantidad de leche, o en gallinas, la cantidad y calidad de los huevos. El humano también ha seleccionado la fuerza o velocidad en diferentes razas de caballos, o comportamientos complejos y útiles, como las características de las diferentes variedades de perros: pastores (que guían al ganado y lo juntan), o para cacerías de diferente tipos, por ejemplo, que siguen a las presas por el olfato, las señalen, o las recojan una vez abatida la presa. También hay perros seleccionados para vigilancia o compañía, así se han conseguido razas de perros de compañía que en muchos casos son extraños o especialmente feos o bonitos. Diferentes estudios recientes de domesticación en animales, incluyendo una amplia revisión de la domesticación de los perros, se reseñan en la obra de Francis (2015), que además incluye una extensa bibliografía.

En concreto, las presiones selectivas ejercidas sobre los animales y plantas domesticados favorecen cambios fenotípicos en los caracteres que son de interés para el domesticador, lo cual conlleva a una divergencia morfológica, fisiológica y genética entre el organismo domesticado y su pariente silvestre, que en algunos casos pueden implicar que la cruza entre la variedad silvestre y la domesticada sea difícil, o hasta imposible. En ciertos casos ha sido muy difícil encontrar a las poblaciones silvestres, ya que la forma domesticada es muy diferente a la original. Este es el caso del maíz, donde hasta muy recientemente se aceptó de manera general que su ancestro silvestre son los teosintes del centro de México (Mangelsdorf, 1974; Solbrig \& Solbrig, 1994; Kato et al., 2009; Bennetzen et al., 2001; Eguiarte et al., 2013; Aguirre Liguori et al., 2016). A veces se considera a la domesticación como un ejemplo de coevolución mutualista, ya que inclusive el humano no sólo cambia a las especies de animales, plantas o aun microbios (como las levaduras del pan y la cerveza) domesticadas, sino que la interacción con ellos ha cambiado nuestro genoma por selección natural (Purugganan 
\& Fuller, 2009; Laland et al., 2010). Un caso muy interesante es el de la tolerancia a la lactosa en humanos adultos, que ha evolucionado de manera independiente varias veces, debido al incremento en el consumo de productos lácteos gracias a la domesticación de animales como vacas y cabras para obtener leche (Simoons, 1970; Beja-Pereira et al., 2003; Ingram et al., 2009; Gerbault et al., 2011), o la tolerancia al alcohol en humanos (Han et al., 2007; Laland et al., 2010), que es un caso más complejo, donde se seleccionaron granos (semillas), frutas y otras partes de las plantas (como en el caso de los agaves o de la caña de azúcar), que junto con las levaduras producen el alcohol, cambiando nuestro genoma y fisiología de la tolerancia al etanol; aunque hay una fuerte variación geográfica entre las poblaciones humanas al respecto (Chen, et al., 1999; Han et al., 2007; Laland et al., 2010).

La domesticación puede ser un largo proceso con varios pasos intermedios. Como se indicó en líneas anteriores, se puede definir a un organismo como totalmente domesticado cuando depende completamente de los humanos para su sobrevivencia y reproducción. Ejemplos de organismos totalmente domesticados son el maíz y el frijol. Pero hay etapas intermedias, que se conocen como de domesticación parcial o incipiente, en las que ya han cambiado algunas características, pero los organismos aún pueden sobrevivir y reproducirse sin ayuda de los humanos. Así, diferentes especies de plantas y animales en distintas etapas de la domesticación pueden regresar a la naturaleza y volver a vivir como organismos silvestres, aunque conservando algunos cambios evolutivos incipientes que ocurrieron en la domesticación. Estos organismos se definen como escapados, mismos que pueden llegar a ser especies invasoras, algunas de ellas muy dañinas para los ecosistemas, como es el caso de los gatos ferales en todo el mundo, especialmente en islas donde pueden acabar, en poco tiempo, con grupos completos de especies endémicas de aves y mamíferos pequeños (e.g., Medina \& Nogales, 2009; Aguirre-Muñoz et al., 2015).

Recientemente, el desarrollo de métodos moleculares ha permitido avances notables en el estudio moderno de la domesticación (Purugganan \& Fuller, 2009; Meyer \& Purugganan, 2013; Gaut, 2015; Gaut et al., 2015). Actualmente, se pueden secuenciar genomas completos muy rápidamente, a un costo relativamente modesto, analizar las diferencias entre todo el genoma de las plantas u otros organismos silvestres y cómo cambiaron a consecuencia de la domesticación. También se pueden usar diferentes marcadores genéticos, para evaluar geográficamente dónde se domesticaron las diferentes especies, estimar hace cuánto tiempo sucedieron los cambios fisiológicos y morfológicos, cómo cambiaron sus tamaños efectivos, cuáles características y/o genes fueron los blancos de la selección y la intensidad de esta selección, entre otros procesos evolutivos (Eguiarte et al., 2013; Escalante et al., 2014; Gaut, 2015; Gaut et al., 2015).
Así, como inicialmente describió Charles Darwin (1859), la domesticación es un sistema especialmente útil para estudiar procesos evolutivos, como la adaptación, la especiación, la evolución de los organismos y sus genes, debido a que los cambios son rápidos con presiones de selección que pueden ser muy grandes, y muchas veces es relativamente fácil identificar los genes afectados por la selección artificial (Eguiarte et al., 2013; Meyer \& Purugganan, 2013; Gaut, 2015; Gautetal., 2015). Para una introducción a los conceptos básicos de evolución, se puede revisar Eguiarte (1986) o Piñero (1987).

Actualmente, estamos observando grandes avances en el estudio de la genética de las especies domesticadas, debido a su relevancia económica e importancia para la alimentación mundial; estos datos genéticos a su vez facilitan los estudios ecológicos y evolutivos de la domesticación y de la variación poblacional de estas especies (Hancock, 2005; Eguiarte et al., 2013; Meyer \& Purugganan, 2013; Gepts, 2014). El análisis conjunto de los datos genéticos y ecológicos puede revelar información importante sobre caracteres de relevancia agronómica, que eventualmente podrían ayudar en el mejoramiento de estas especies (Gustafson et al., 2008; Hufford et al., 2012a; Meyer \& Purugganan, 2013). Con esta información, en el futuro próximo se van a poder realizar análisis predictivos de respuesta de la variación en escenarios de cambio ambiental, no sólo usando la distribución potencial, como se ha hecho en el teosinte, el maíz silvestre (Hufford et al., 2012b; Aguirre-Liguori et al., manuscrito enviado b), sino también analizando la distribución de la diversidad genética en el futuro y como alelos particulares nos podrán ayudar ante escenarios de cambio climático, sequía, limitación de nutrientes $\mathrm{o}$ ataque de plagas, virus y enfermedades (Aguirre-Lugori et al., manuscrito enviado a).

\section{Recursos genéticos vegetales en México}

México es un país con una gran biodiversidad agrícola y cultural además de ser un centro de origen, domesticación y diversificación de una gran cantidad de cultivos (CONABIO, 2006; Zizumbo-Villarreal \& Colunga-GarcíaMarín, 2010), por lo que obviamente es de gran interés estudiar, conservar y utilizar de forma sostenible su diversidad genética y de especies, sobre todo considerando el contexto actual del cambio climático (CONABIO, 2006; Dirzo et al., 2014; Álvarez-Yépiz \& Martínez-Yrízar, 2015; Eguiarte et al., 2017). Esta tarea nos toca a los científicos mexicanos, y es una labor urgente, dada la extensa destrucción ambiental que sufre todo el territorio del país, que sólo se va a intensificar con el cambio climático acelerado (CONABIO, 2006; Álvarez-Yépiz \& Martínez-Yrízar, 2015).

Los recursos fitogenéticos se pueden definir como las plantas que han sido seleccionadas y conservadas por los agricultores de forma tradicional (Allem, 2000; FAO, 2011). Estas plantas y sus genes tienen un valor actual con potencial para la alimentación y la agricultura, constituyen la base biológica de la producción agrícola para la seguridad alimentaria nacional y mundial, en 
este momento así como en el futuro. La diversidad genética de los recursos fitogenéticos está integrada por la variación genética, tanto de las diferentes variedades, así como de las especies cultivadas y de las especies silvestres cercanas (Allem, 2000; FAO, 2011).

El estudio de la diversidad genética ayuda a la conservación y al uso sostenible de estos recursos genéticos, ya que por ejemplo, puede permitir la adaptación de los cultivos a condiciones de estrés biótico o abiótico, mitigando los efectos de la "erosión genética" causada por la sustitución de las variedades locales por variedades comerciales, y servir como un amplio reservorio de diversidad genética útil para seleccionar diferentes características morfológicas, fisiológicas, etc., que sean relevantes en el manejo futuro de una especie (FAO, 2011; Eguiarte et al., 2013, 2017).

Recientemente se han realizado diferentes estudios enfocados al análisis de la variación genética en especies cultivadas y/o en sus parientes silvestres, empleando no sólo diferentes marcadores moleculares, sino ya a nivel genómico, usando información de muchos - miles o millones de sitios de DNA — o genomas completos. Estos estudios han revelado loci(genes) candidatos a cambios por selección durante la domesticación (Eguiarte et al., 2013; Meyer \& Purugganan, 2013; Gepts, 2014; AguirreLiguori et al., 2017; Fustier et al., 2017;). Estos genes explican diferencias morfológicas además de bioquímicas entre taxa domesticados y sus parientes silvestres (Qi et al., 2013; Shang et al., 2014).

Por ejemplo, recientemente se han publicado estudios genómicos enfocados a la domesticación en plantas originarias de México, que son parte de la milpa, como el maíz (Hufford et al., 2012a; Jiao et al., 2012; Romay et al., 2013; Moreno-Letelier et al., 2018), el frijol común y el frijol ayocote (Schmutz et al., 2014; Guerra-García et al., 2017), o el chile(Qin etal., 2014). También se están realizado estudios similares en cultivos de importancia mundial como el jitomate (Koenig et al., 2013; Lin et al., 2014), la soya (Lam et al., 2010; Li et al., 2013), el arroz (Xu et al., 2011) y el pepino(Qi et al., 2013; Shang et al., 2014), entre otros. A continuación vamos a revisar con cuidado nuestros estudios que tratan sobre los recursos genéticos y la domesticación en las calabazas de México, inciando con una descripción de las especies del género, tanto silvestres como cultivadas.

\section{Historia natural y biología de las calabazas}

Las calabazas pertenecen al género Cucurbita, de la familia Cucubitaceae. Son llamadas zapallos en Sudamérica y es un grupo de plantas herbáceas nativas del continente americano que presentan frutos del tipo pepo (Lira et al., 2009 a y b). El género incluye de 12 a 15 especies, y en total unos 20 taxa tomando en cuenta a las subespecies, la mayor parte de sus taxa se distribuyen en México (Paris, 2016; Lira, 1995; Lira et al., 2016).
Cucurbita se considera como uno de los géneros con mayor variedad morfológica (hojas, frutos, flores, semillas, etc.) en las angiospermas (Bisognin, 2002). Tanto las especies silvestres como las cultivadas del género son plantas monoicas (las flores son masculinas (estaminadas) o femeninas (pistiladas)), rastreras o trepadoras. Las flores son gamopétalas, sus pétalos están fusionados en una gran flor, tubular y campanulada, su color varía entre amarillo pálido a tonos amarillos brillantes. Las plantas producen muchas más flores masculinas que femeninas (Lira, 1995: Lira et al., 2016), mismas que normalmente son polinizadas por abejas solitarias del género Peponapis y Xenoglosa, que visitan las flores al amanecer, cuando abren; aunque las flores también pueden ser visitadas y polinizadas por otras abejas, incluyendo Apis mellifera, la abeja europea (Hurd et al., 1971; Montes-Hernández, 2002). Las abejas visitan todas las especies de Cucurbita de manera indiscriminada, por lo que si crecen varios taxa cercanos, puede haber flujo genético e hibridación entre los taxa silvestres y cultivados emparentados (Montes-Hernández, 2002; Montes-Hernández \& Eguiarte, 2002).

Los frutos de las especies de Cucurbita son en general grandes, especialmente en algunas especies cultivadas. En las especies y variedades silvestres los frutos son más pequeños y relativamente uniformes en forma, superficie, tamaño y coloración, además de ser muy amargos debido a un compuesto químico, la cucurbitacina, un esteroide que las defiende de los herbívoros.

\section{Origen y filogenia de las calabazas}

El género Cucurbita tuvo un origen relativamente reciente, hace $16 \pm 7$ millones de años, desde la divergencia con su género hermano, Peponopsis (Schaefer et al., 2009; Paredes-Torres, 2016; Castellanos-Morales et al., 2018). Se han realizado diferentes estudios para inferir las relaciones filogenéticas entre las diferentes especies de calabazas (Sanjur et al., 2002; Zheng et al., 2013; Kistler et al., 2015; Paredes-Torres, 2016; Kates et al., 2017; Castellanos et al., 2018; Figura 1). Por ejemplo, recientemente se publicaron filogenias usando datos obtenidos del transcriptoma (los datos que se obtienen de secuenciar su RNA, es decir, el material genético ya transcrito (del DNA a RNA), que contiene información que da origen a las proteínas e información para otras moléculas con función regulatoria y de traducción, como veremos posteriormente) de once taxa del género (Montero-Pau et al., 2017). Otro esfuerzo importante es el realizado por Kates et al. (2017), donde utilizaron 44 loci nucleares con 20 taxa del género, incluyendo varios ejemplares de cada taxón. Estos estudios, aunque técnicamente impresionantes, presentan incertidumbres sobre la posición filogenética de especies importantes como el chilacayote, $C$. ficifolia, y no incluyen a una importante especie silvestre, C. radicans.

Recientemente se ha avanzado en el estudio de la filogenia usando secuencias del cloroplasto que resuelven la posición 


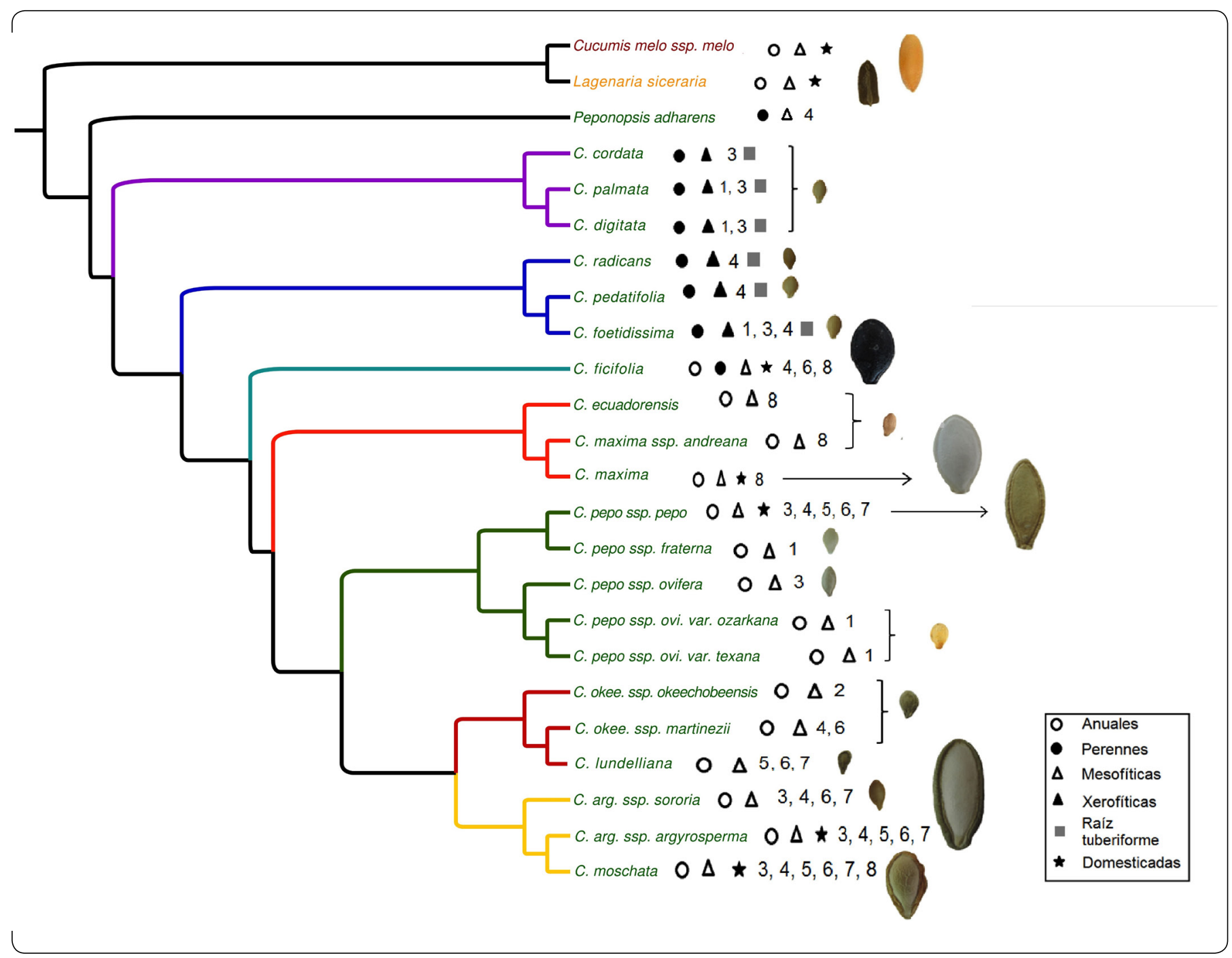

Figura 1. Filogenia de Cucurbita resaltando cada clado o grupo con un color distinto. Morado: grupo Digitata; azul: grupo Foetidissima; verde-agua: C. ficifolia; naranja: grupo Maxima (calabazas sudamericanas); verde: grupo Pepo; rojo: grupo Okeechobeensis; amarillo: grupo Argyrosperma; los grupos externos se observan en color negro). Los nombres en color verde denotan especies de origen Americano (todo el género Cucurbita), en amarillo de origen Africano (i.e., Cucumis melo ssp. melo) y en rojo de origen Asiático (Lagenaria siceraria). Se señalan con una estrella a las especies domesticadas. Los símbolos se refieren a distintas características como mesofíticas (climas húmedos) o xerofíticas (de climas áridos); tipo de raíz (tuberiforme: con estructuras de almacenamiento); anuales o perennes (verdes todo el año), como se indica en el recuadro en la figura. El número corresponde al área de distribución de cada especie, 1, Estados Unidos; 2, Península de Florida; 3, Norte de México; 4, Centro de México; 5 Península de Yucatán, 6, Sur de México; 7 Centroamérica, 8, Sudamérica, y se muestra la foto de la semilla a escala, de manera que se puede apreciar que las especies domesticadas presentan gigantismo en las semillas. Topología obtenida utilizando secuencias de DNA de cloroplasto. Figura modificada de Paredes-Torres (2016).

de dichas especies, e incluyen todos los taxa generalmente reconocidos en el género (Paredes-Torres, 2016; CastellanosMorales et al., 2018; Figura 1). Los resultados muestran que los distintos taxa se agrupan siguiendo sus características ecológicas, fisiológicas y su distribución. Así, las especies xerofíticas perennes (de climas áridos) son las que divergen más temprano en la filogenia, mientras que los grupos más recientes están conformados por especies mesofíticas anuales (de climas más húmedos) y se distribuyen en áreas tropicales (Figura 1). Así, la diversificación de las calabazas se relaciona con los cambios climáticos del Pleistoceno en Norte América y Mesoamérica que promovieron desplazamientos en sus áreas de distribución. Las calabazas ancestralmente se encontraban en el norte de México y California y en regiones muy áridas y estacionales (Baja California, desiertos del sur de California y Sonora), con el tiempo se adaptaron a condiciones más templadas, avanzando hacia el centro de México (Faja Volcánica Transmexicana), mientras que los linajes más recientes se encuentran en lugares 
cada vez más al sur, inicalmente en regiones climáticamente menos extremas. Finalmente, las calabazas llegaron a lugares tropicales húmedos y muy calientes, como las regiones del sur de México, toda la Costa del Golfo de México desde Florida, y Texas, hasta la Península de Yucatán, donde actualmente proliferan las especies que divergieron hace relativamente poco, unos cientos de miles de años o menos.

\section{El CULtivo de las calabazas}

Las calabazas en México y en el resto de Mesoamérica son parte importante del sistema de la milpa y otras formas de policultivo, ya que si bien su producción no es tan importante en toneladas como el maíz o el frijol, son un componente crítico de la milpa, al mitigar la erosión del suelo, mantener su humedad gracias a sus hojas, anchas y gruesas que forman una densa capa sobre la superficie, reduciendo además el establecimiento y crecimiento de malezas (Altieri, 1995; Gliessman, 1983, 1990; LozadaAranda et al., 2017; Sánchez de la Vega, 2017).

Las calabazas son cultivos de alta importancia a nivel mundial y parte central de la alimentación en muchas regiones del mundo, como China, India y diferentes países de Europa, América y África (Lira et al., 2009b). Paradójicamente, hasta el momento existen pocos estudios sobre sus recursos genéticos (Lira et al., 2009b, 2016), especialmente en México, su centro de diversidad y domesticación donde carecemos hasta ahora de estudios a nivel genómico donde se analice explícitamente su domesticación.

Las especies cultivadas de Cucurbita destinadas a la alimentación humana tienen gran diversidad en el tamaño, forma, color, ornamentación de los frutos, que no son amargos (Figura 2), por lo que se pueden consumir de la misma manera que sus semillas,

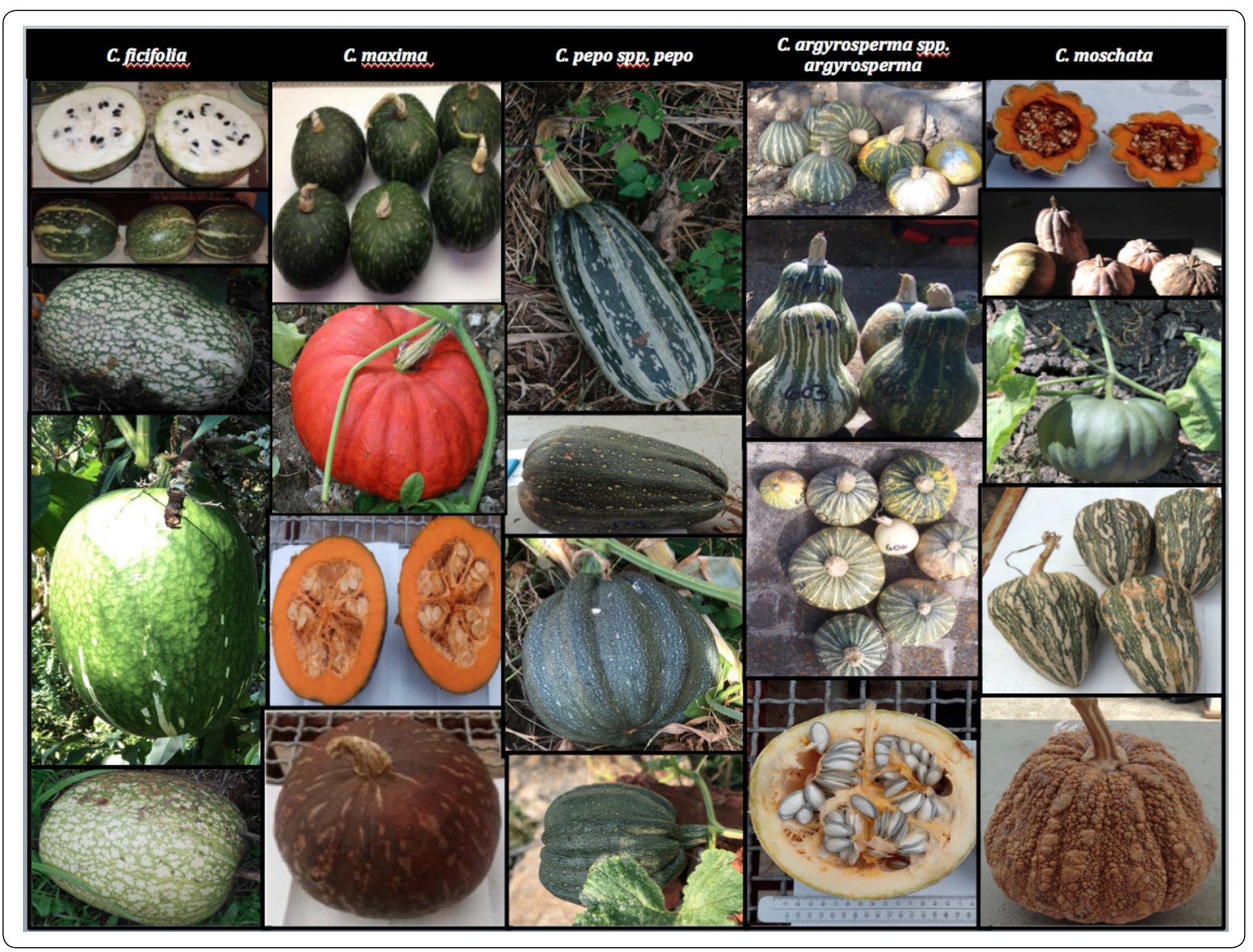

Figura 2. Diversidad morfológica de calabazas domesticadas (género Cucurbita). Fotos: C. maxima naranja, J.H. Mora (2001). Potiron 'rouge vif d'Étampes' (Cucurbita maxima). Wikipedia, actualizado 06 de Agosto de 2006. Gabriela Castellanos Morales, Helena S. Hernández-Rosales, Guillermo Sánchez de la Vega y Leslie Paredes-Torres. 
flores y guías. Los frutos de las formas cultivadas pueden llegar a ser realmente muy grandes, llegando a pesar hasta $45 \mathrm{~kg}$ o más en ciertas variedades e individuos; el record mundial de peso de una calabaza es de 1,190.5 kg (https://en.wikipedia.org/ wiki/Giant_pumpkin). Las formas cultivadas tienen también un mayor tamaño en las hojas, semillas, frutos y flores.

\section{ESPECIES DOMESTICADAS DEL GÉNERO Cucurbita}

Cucurbita ha tenido cuando menos cinco eventos independientes de domesticación, que en su mayoría sucedieron en México (Nee, 1990; Zheng et al., 2013) (Tabla I; Figura 1 y 2). Por ejemplo, C. pepo, la calabacita que se consume como verdura o zucchini, tal vez fue domesticada una vez en México y otra en EUA (Paredes-Torres, 2016; Castellanos-Morales et al., 2018), mientras que C. maxima fue domesticada en Sudamérica, aunque aún se necesitan más estudios para poder decir más sobre su domesticación y cómo sucedió. C. ficifolia, el chilacayote, seguramente fue domesticado en Mesoamérica y en nuestros estudios encontramos que $C$. moschata, llamada calabaza de castilla, se agrupa con otros dos taxa de C. argyrosperma (Figura 1), uno de ellos es la subespecies domesticada, C. argyrosperma spp. argyrosperma, conocida comúnmente como calabaza pipiana; estos tres taxa forman al grupo Argyrosperma, que también fue domesticado en Mesoamérica (Lira et al., 2009 a y b), en dos eventos independientes de domesticación (Nee, 1990; Zheng etal.,2013; Figura 3). Para C. moschata aún se desconoce su especie hermana silvestre, que tal vez esté extinta actualmente (Nee, 1990). Estos tres taxa son polinizados principalmente, como mencionamos antes por abejas especialistas de los géneros Peponapis y Xenoglossa, siendo frecuente el entrecruzamiento entre el taxón silvestre y los dos taxa domesticados (Montes Hernández, 2002; Lira et al., 2009b).

Los registros arqueológicos más antiguos del género corresponden al hallazgo de restos de calabazas (semillas y fragmentos de fruto) de $C$. pepo de hace unos 8,000 años en la cueva Guilá Naquitz, en Oaxaca. Estos datos permitieron determinar que las calabazas fueron las primeras plantas

\begin{tabular}{|c|c|c|c|c|c|}
\hline & C. ficifolia & C. maxima & C. реро spp. реро & $\begin{array}{c}\text { C. argyrosperma spp. } \\
\text { argyrosperma }\end{array}$ & C. moschata \\
\hline Tallo & $\begin{array}{l}\text { Vigorosos, } \\
\text { ligeramente } \\
\text { angulosos. }\end{array}$ & $\begin{array}{l}\text { Engrosados, } \\
\text { redondeados o } \\
\text { muy ligeramente } \\
\text { angulosos. }\end{array}$ & Angulosos y surcados. & Angulosos y surcados. & $\begin{array}{l}\text { Angulosos cuando verdes } \\
\text { y aparecen surcos al } \\
\text { secarse. }\end{array}$ \\
\hline Hoja & $\begin{array}{l}\text { Láminas con } \\
\text { 3-5 lóbulos } \\
\text { (redondeados), } \\
\text { el central es más } \\
\text { grande que los } \\
\text { laterales, márgenes } \\
\text { denticulados. }\end{array}$ & $\begin{array}{l}\text { Tamaño variable. } \\
\text { Ligeramente o } \\
\text { nada lobada. } \\
\text { Márgenes enteros } \\
\text { a denticulados, } \\
\text { ambas superficies } \\
\text { pubescentes. }\end{array}$ & $\begin{array}{l}\text { Grandes }(>20 \mathrm{~cm}) \text {. } \\
\text { Anchas ovado- } \\
\text { cordadas a triangular, } \\
\text { lobadas (profundos } \\
\text { triangulares a } \\
\text { rómbico-elípticos, } \\
\text { ápice redondeado). } \\
\text { Márgenes } \\
\text { denticulados a } \\
\text { serrado-denticulados. }\end{array}$ & $\begin{array}{l}\text { Grandes }(>20 \mathrm{~cm}) \text {. } \\
\text { Profundamente lobadas } \\
\text { (son triangulares y } \\
\text { obtusas). Márgenes } \\
\text { denticulados a incisos. } \\
\text { El haz con manchas } \\
\text { blancas. }\end{array}$ & $\begin{array}{l}\text { Grandes }(>20 \mathrm{~cm}) . \text { Con } \\
\text { margenes aserrados. } \\
\text { Ligeramente lobadas } \\
\text { (ovadas o triangulares, } \\
\text { ápice obtuso). El haz con } \\
\text { manchas blancas en la } \\
\text { intersección de las venas. }\end{array}$ \\
\hline $\begin{array}{l}\text { Flores } \\
\text { (masculinas } \\
\text { y femeninas) }\end{array}$ & $\begin{array}{l}\text { No aromáticas. } \\
\text { Color amarillo } \\
\text { claro. Lóbulos } \\
\text { agudos, márgenes } \\
\text { enteros ondulados } \\
\text { y doblándose hacia } \\
\text { adentro). Ovario } \\
\text { ovoide a elíptico. }\end{array}$ & $\begin{array}{l}\text { Aromáticas. Color } \\
\text { amarillo brillante. } \\
\text { Lóbulos anchos, } \\
\text { reflexos, márgenes } \\
\text { crispados. Ovario de } \\
\text { muy diversas formas, } \\
\text { pubescente. }\end{array}$ & $\begin{array}{l}\text { No aromáticas. Color } \\
\text { anaranjado. Lóbulos } \\
\text { agudos a acuminados, } \\
\text { obtusos, márgenes } \\
\text { enteros ondulados } \\
\text { y doblándose hacia } \\
\text { adentro. Ovario liso } \\
\text { y diverso (globoso, } \\
\text { ovoide, cilíndrico a } \\
\text { raramente piriforme). }\end{array}$ & $\begin{array}{l}\text { No aromáticas. Color } \\
\text { amarillo con blanco y } \\
\text { anaranjado en el limbo. } \\
\text { Lóbulos agudos, obtusos, } \\
\text { con los márgenes enteros } \\
\text { pero ondulados. Ovario } \\
\text { globoso a piriforme. }\end{array}$ & $\begin{array}{l}\text { No aromáticas. Color } \\
\text { amarillo-anaranjado. } \\
\text { Lóbulos triangulares, } \\
\text { agudos a acuminados, } \\
\text { márgenes enteros } \\
\text { ondulados y doblados } \\
\text { hacia adentro. Ovario } \\
\text { diverso (globoso, ovoide, } \\
\text { cilíndrico, piriforme, } \\
\text { cónico). }\end{array}$ \\
\hline
\end{tabular}

Tabla I. Principales características de las especies domesticadas del género Cucurbita (Lira, 1995; Lira et al., 2009 a y b; Villanueva, 2007). 


\begin{tabular}{|c|c|c|c|c|c|}
\hline & C. ficifolia & C. maxima & C. реро spp. реро & $\begin{array}{c}\text { C. argyrosperma spp. } \\
\text { argyrosperma }\end{array}$ & C. moschata \\
\hline $\begin{array}{l}\text { Forma del } \\
\text { fruto }\end{array}$ & $\begin{array}{l}\text { Globoso, ovado o } \\
\text { elíptico. Cáscara } \\
\text { rígida, dura, } \\
\text { gruesa, durable, sin } \\
\text { costillas, densa y } \\
\text { poco arrugada. }\end{array}$ & $\begin{array}{l}\text { Diversas formas } \\
\text { (turbaniformes). } \\
\text { Algunos muy grandes } \\
(100 \mathrm{~kg} .) \text {. Lisos o } \\
\text { con suaves costillas } \\
\text { redondeadas. Cáscara } \\
\text { rígida o suave. }\end{array}$ & $\begin{array}{l}\text { De forma costado- } \\
\text { anguloso. Pocas veces } \\
\text { lisos. Cáscara rígida y } \\
\text { dura a suave, algunas } \\
\text { veces verrucosa. }\end{array}$ & $\begin{array}{l}\text { Periforme o claviforme, } \\
\text { la parte más delgada } \\
\text { recta o encorvada. } \\
\text { Cáscara rígida con } \\
\text { excrecencias leñosas que } \\
\text { parecen escurrirse desde } \\
\text { el pedúnculo. }\end{array}$ & $\begin{array}{l}\text { Forma y tamaño diverso } \\
\text { conservando la forma } \\
\text { del ovario. Lisos o } \\
\text { comunmente con costillas } \\
\text { redondeadas. Cáscara } \\
\text { engrosada, rígida y } \\
\text { durable o suave y } \\
\text { perecedera. }\end{array}$ \\
\hline $\begin{array}{l}\text { Color del } \\
\text { fruto }\end{array}$ & $\begin{array}{l}\text { Tres patrones: } \\
\text { a) verde claro } \\
\text { u oscuro, con } \\
\text { o sin franjas } \\
\text { longitudinales } \\
\text { blancas. b) } \\
\text { manchado de } \\
\text { blanco o verde. c) } \\
\text { blanco o crema. }\end{array}$ & $\begin{array}{l}\text { Incluyen el azul- } \\
\text { grisáceo, verde } \\
\text { parduzco, rosado } \\
\text { y rojo o rojizo- } \\
\text { anaranjado. }\end{array}$ & $\begin{array}{l}\text { Totalmente verde } \\
\text { claro a oscuro. } \\
\text { Diminutamente } \\
\text { moteado en crema o } \\
\text { amarillo. }\end{array}$ & $\begin{array}{l}\text { De blanco hasta verde } \\
\text { oscuro. Manchas, } \\
\text { sombreados o más } \\
\text { común granjas } \\
\text { retículadas blancas a } \\
\text { amarillas. }\end{array}$ & $\begin{array}{l}\text { Patrones de color muy } \\
\text { variable que van del } \\
\text { verde oscuro a claro. } \\
\text { Liso o con manchas } \\
\text { crema. Cubierta cerosa } \\
\text { blanquecina. }\end{array}$ \\
\hline Pulpa & $\begin{array}{l}\text { Notoriamente } \\
\text { fibrosa. Blanca. } \\
\text { Sabor dulce. }\end{array}$ & $\begin{array}{l}\text { Ligeramente } \\
\text { fibrosa. Diferentes } \\
\text { tonalidades de } \\
\text { amarillo a anaranjado. } \\
\text { Sabor ligeramente } \\
\text { suave. }\end{array}$ & $\begin{array}{l}\text { Ligeramente fibrosa } \\
\text { de sabor no amargo } \\
\text { a fibrosa y sabor } \\
\text { muy amargo (estas } \\
\text { últimas de cultivares } \\
\text { ornamentales). }\end{array}$ & $\begin{array}{l}\text { Ligeramente fibrosa. } \\
\text { Amarilla o anaranjada } \\
\text { de pálida a brillante, } \\
\text { algunas veces verde } \\
\text { obscuro a negro. Sabor } \\
\text { dulce. }\end{array}$ & $\begin{array}{l}\text { Abundante usualmente } \\
\text { no fibrosa de consistencia } \\
\text { suave. Amarilla en } \\
\text { distintas tonalidades } \\
\text { a anaranjada, a veces } \\
\text { verdosa. Sabor dulce. }\end{array}$ \\
\hline Pedúnculo & $\begin{array}{l}\text { Delgado y rígido, } \\
\text { anguloso con } \\
\text { costillas o crestas } \\
\text { obtusas. Poco } \\
\text { ensanchado en la } \\
\text { unión con el fruto. }\end{array}$ & $\begin{array}{l}\text { Corto, suave rígido. } \\
\text { Cilíndrico o no } \\
\text { anguloso, con estrías } \\
\text { corchosas irregulares. }\end{array}$ & $\begin{array}{l}\text { Grueso, rígido } \\
\text { anguloso. Presenta } \\
\text { costillas agudas } \\
\text { que se extienden y } \\
\text { ensanchan hacia el } \\
\text { ápice del fruto. }\end{array}$ & $\begin{array}{l}\text { Notablemente } \\
\text { engrosado, cilíndrico, } \\
\text { claviforme o subgloboso, } \\
\text { corchoso. Rígido a } \\
\text { leñoso. }\end{array}$ & $\begin{array}{l}\text { Rígido, leñoso, anguloso. } \\
\text { Con costillas que se } \\
\text { extienden hacia el ápice y } \\
\text { ensanchado hacia el ápice } \\
\text { del fruto. }\end{array}$ \\
\hline Semillas & $\begin{array}{l}\text { Generalmente } \\
\text { negras, aunque } \\
\text { existen en baja } \\
\text { frecuencia de color } \\
\text { crema y pardo. } \\
\text { Márgenes poco } \\
\text { diferenciados del } \\
\text { mismo color que la } \\
\text { semilla. }\end{array}$ & $\begin{array}{l}\text { Gruesas, elípticas } \\
\text { infladas o } \\
\text { tumescentes. } \\
\text { Bronceadas (color } \\
\text { canela) blancas } \\
\text { a pardo claras. } \\
\text { Lisas o muy poco } \\
\text { estriadas. Márgenes } \\
\text { redondeados } \\
\text { diferenciados del } \\
\text { color del centro. }\end{array}$ & $\begin{array}{l}\text { Angostas o } \\
\text { anchamente } \\
\text { elípticas. Planas o } \\
\text { poco tumescentes. } \\
\text { Dentro liso blanco en } \\
\text { distintas tonalidades } \\
\text { y márgenes bien } \\
\text { diferenciados (simple } \\
\text { o con surco doble) del } \\
\text { mismo color que el } \\
\text { centro. }\end{array}$ & $\begin{array}{l}\text { Elípticas o lanceoladas. } \\
\text { Comprimidas o } \\
\text { planas. Lisas o con } \\
\text { pequeñas cicatrices } \\
\text { o escarificaciones } \\
\text { profundas. Blancas } \\
\text { opaco a pardo oscuro. } \\
\text { Márgenes bien definidos } \\
\text { del centro de la semilla } \\
\text { (pardos, grises o } \\
\text { dorados.) }\end{array}$ & $\begin{array}{l}\text { Elípticas u ovado- } \\
\text { elípticas. Blancas o } \\
\text { pardo claras del centro } \\
\text { y márgenes bien } \\
\text { diferenciados en color y } \\
\text { textura. Ápice obtuso a } \\
\text { truncado. }\end{array}$ \\
\hline Distribución & $\begin{array}{l}\text { Desde México } \\
\text { hasta Argentina y } \\
\text { Chile. }\end{array}$ & $\begin{array}{l}\text { Norte de México } \\
\text { (poca documentación } \\
\text { de los cultivos en la } \\
\text { actualidad). Sur de } \\
\text { América (Argentina, } \\
\text { Bolivia, Uruguay). }\end{array}$ & $\begin{array}{l}\text { Se cultiva en todos los } \\
\text { continentes. }\end{array}$ & $\begin{array}{l}\text { Desde el suroeste de } \\
\text { Estados Unidos hasta } \\
\text { Centroamérica. }\end{array}$ & $\begin{array}{l}\text { Mesoamérica hasta Sur } \\
\text { de América. }\end{array}$ \\
\hline $\begin{array}{l}\text { Nombre } \\
\text { común }\end{array}$ & $\begin{array}{l}\text { Chilacayote. } \\
\text { Chilaca. }\end{array}$ & $\begin{array}{l}\text { Calabaza chihua o de } \\
\text { pepita rusa. Kabocha. }\end{array}$ & $\begin{array}{l}\text { Calabacín, } \\
\text { calabacines, } \\
\text { tempranilla, calabaza } \\
\text { de manteca, zucchini. }\end{array}$ & $\begin{array}{l}\text { Calabaza pipiana, pinta } \\
\text { o rayada. }\end{array}$ & $\begin{array}{l}\text { Calabaza de castilla, } \\
\text { de casco o pellejo. } \\
\text { Cuaresmeña, támala, } \\
\text { sequola. }\end{array}$ \\
\hline
\end{tabular}

Tabla I. Principales características de las especies domesticadas del género Cucurbita (Lira, 1995; Lira et al., 2009 a y b; Villanueva, 2007 ) (continuación). 


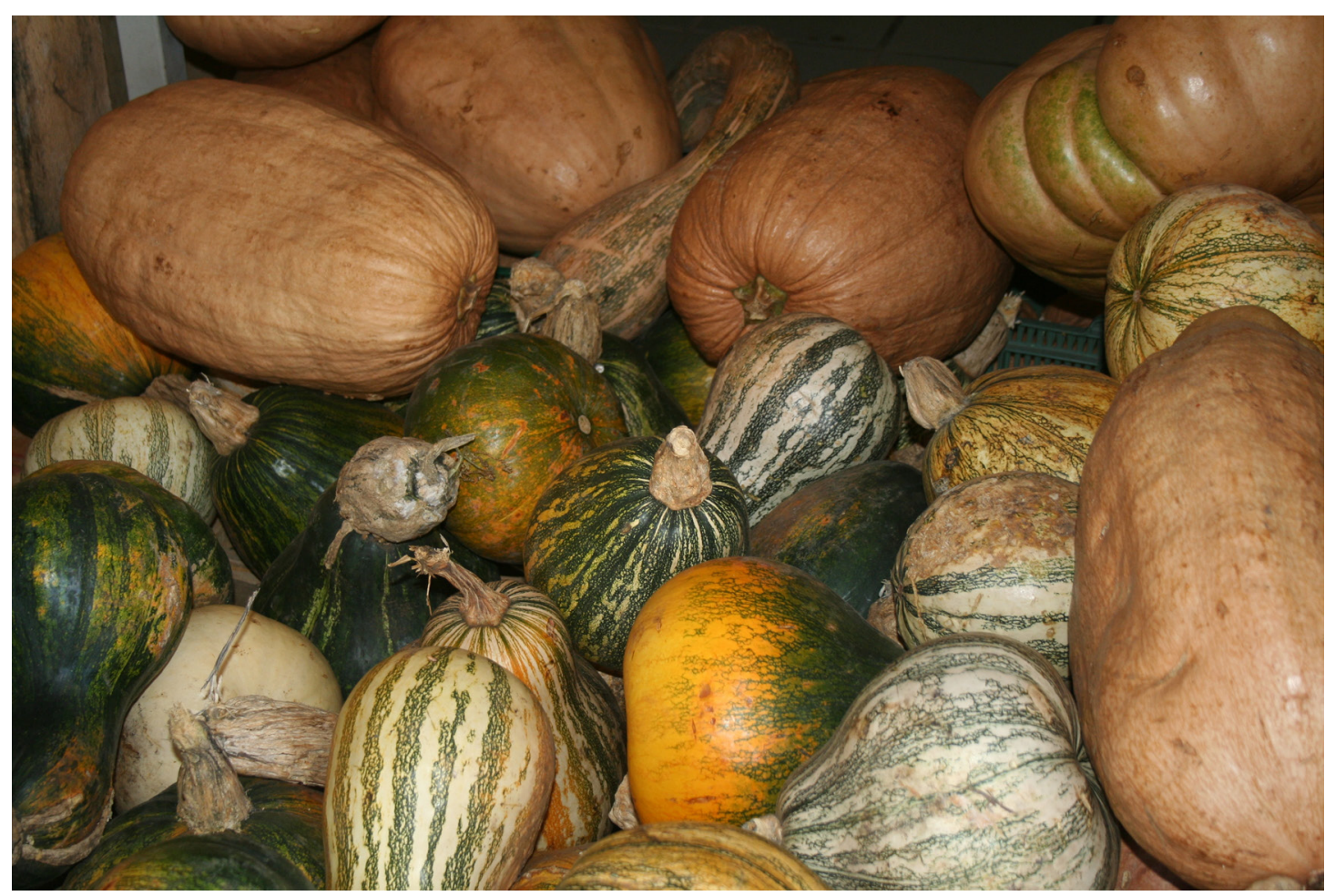

Figura 3. Diversidad morfológica observada en $C$. moschata (calabazas muy grandes de color beige o café claro que se aprecian en la parte superior de la fotografía) y $C$. argyrosperma (calabazas medianas de color verde con franjas o manchas bien marcadas, frutos generalmente en forma de pera con pedúnculos gruesos que se aprecian en la parte inferior de la fotografía). Foto: Gabriela Castellanos Morales.

domesticadas en México, tal vez miles de años antes que el maíz y el frijol, que después conformaron juntos la milpa. También se registraron restos de $C$. argyrosperma ssp. argyrosperma y C. moschata de más de 7 mil años, y de 6.9-5.5 mil años de antigüedad, respectivamente (Whitaker, 1981; Sánchez-de la Vega, 2017).

Actualmente, se están realizando diferentes análisis evolutivos a nivel genómico y de genética de poblaciones, así como de la filogeografía en diferentes especies del género, principalmente en las cultivadas y en sus parientes silvestres de las que fueron domesticadas. A continuación nos vamos a concentrar en describir los avances en el estudio de C. argyrosperma tanto silvestre como cultivada y C. moschata cultivada, ya que no existe de forma silvestre) además de C.pepo silvestre y cultivada.

\section{Genética de poblaciones, filogeografía y ReCursos GENÉTICOS EN Cucurbita}

\section{i) Cucurbita argyrosperma silvestre y cultivada}

El cultivo de C. argyrosperma ssp. argyrosperma se ha enfocado al consumo de sus semillas, con menor énfasis en la utilización de sus frutos, flores o tallos (Paris, 2016; Sánchez-de la Vega, 2017). Las poblaciones de su pariente silvestre, C. argyrosperma spp. sororia, se distribuyen por toda la costa del Pacífico en
México y Centroamérica, desde Sonora hasta Nicaragua, con unas poblaciones aisladas en Veracruz y en el Golfo de México (Lira et al., 2009a). Los análisis a nivel poblacional realizados con marcadores moleculares de cloroplasto, mitocondriales y nucleares, sugieren que las variedades de $C$. argyrosperma ssp. argyrosperma, C. moschata y C. pepo ssp. pepo se encuentran genéticamente bien diferenciadas entre si, a pesar de que son cultivadas frecuentemente en parcelas vecinas o cercanas (Sánchez de la Vega et al., 2018; Castellanos-Morales et al., 2018; Hernández-Rosales et al., en preparación). Sin embargo, en algunos casos se han detectado señales de flujo génico considerable entre $C$. argyrosperma ssp. argyrosperma y su contraparte silvestre $C$. argyrosperma ssp. sororia (Sánchez de la Vega et al., 2018) apoyando los resultados iniciales de Montes-Hernández \& Eguiarte (2002).

Recientemente, Sánchez de la Vega et al. (2018) estudiaron la estructura genética y diversidad a lo largo de México de $C$. argyrosperma, de sus dos subespecies, la ssp. argyrosperma (cultivada) y la ssp. sororia (silvestre) usando microsatélites. Se detectaron moderados niveles de variación genética en las poblaciones de estas subespecies y menores a los reportados en C. moschata, con un porcentaje promedio de loci polimórficos de $70 \%$, encontrándose mayor diversidad en la subespecie 
cultivada, argyrosperma (77\%) que en la subespecie silvestre, sororia $(64 \%)$, aunque la variación genética medida como la $H_{E}$ fue similar entre subespecies $\left(H_{E}=0.41\right.$ en argyrosperma; $H_{E}=0.42$ en sororia). Nueve poblaciones de la ssp. argyrosperma mostraron niveles estadísticamente significativos de endogamia (cruza entre parientes). Ambas subespecies están bien diferenciadas, y la diferenciación genética $\left(F_{S T}\right)$ entre poblaciones dentro de cada subespecie varía de moderada, 0.152 , a muy alta, 0.652 , además se estimaron bajos niveles de flujo génico a nivel regional.

Sánchez de la Vega et al. (2018) sugieren que hace relativamente poco tiempo C. argyrosperma ssp. argyrosperma pasó por un "cuello de botella" y que esta reducción en el tamaño poblacional posiblemente estuvo relacionada con su domesticación, seguido de una rápida expansión poblacional. Sus resultados muestran que las poblaciones de Oaxaca son las más cercanamente emparentadas con la subespecie silvestre $C$. argyrosperma ssp. sororia. También se observa una clara diferenciación de las variedades cultivadas en la Península de Yucatán con respecto al resto de México (Sánchez de la Vega et al., 2018). En esta especie aún quedan por describir los patrones de flujo génico a nivel regional asociados a las actividades humanas, así como explorar hipótesis demográficas, y en particular encontrar a las poblaciones genéticamente más cercanas al centro de origen de la especie, utilizando para esto métodos genómicos, ya que como discutiremos más adelante, con las tecnologías de secuenciación de siguiente generación podremos además explorar la historia demográfica e identificar señales de selección en genes de importancia agronómica (ver también Eguiarte et al. (2013); Escalante et al. (2014)).

\section{Cucurbita moschata cultivada}

Curubita moschata es aprovechada de manera amplia, consumiéndose tanto sus frutos maduros e inmaduros, así como sus semillas, tallos y flores, e incluso sus saponinas se utilizan en la producción de jabón (Paris, 2016; Sánchez de la Vega, 2017). La especie exhibe una notable diversidad morfológica de frutos y semillas respecto a color, forma y grosor (Tabla I, Figuras 2 y 3), presenta además variantes en ciclos de vida como las reportadas en Yucatán: xmejen k'uum, de ciclo de vida corto y xnuk k'uum de ciclo largo (Zizumbo-Villareal \& Terán, 1985; Zizumbo-Villareal et al., 2010). Su amplio acervo genético lo demuestra en la gran diversidad de variedades locales y cultivares comerciales (Lira, 1995: Lira et al., 2016).

Debido a que esta calabaza, aunque relevante para México y Centro América es menos importante a nivel mundial que otras especies del género, los esfuerzos hasta el momento por documentar su diversidad y estructura genética han sido escasos. Tradicionalmente se considera que el cultivo de C. moschata se realiza del centro de México y Centro América hasta Sudamérica (Colombia; Whitaker \& Davis, 1962), sin embargo, las colectas realizadas en los últimos años indican que también se cultiva en el Norte de México en estados donde previamente no se había documentado su cultivo (Sonora, Chihuahua y Coahuila). Su extensa distribución en parte se debe a que la especie puede adaptarse a diversas condiciones ecológicas, lo que facilita su cultivo en diferentes ambientes. Si bien es preferentemente cultivada en zonas de baja altitud, clima cálido y alta humedad, tolera un intervalo geográfico-altitudinal relativamente amplio (Lira et al., 2009 a y b, 2016). En México, las variedades locales son normalmente cultivadas en las milpas, huertos y solares. Por otro lado, algunas variedades mejoradas como Butternut pumpkin (híbrido de Gooseneck squash x Hubbard squash) son cultivadas de manera extensiva en el norte de México (Sinaloa) (Hernández Rosales y Sánchez de la Vega observaciones personales).

Cucurbita moschata ha sido estudiada más bien con objetivos comparativos debido a su estrecha relación con el grupo Argyrosperma más que por si misma, por lo tanto la literatura sobre su genética de poblaciones y recursos genéticos es limitada. Por ejemplo, Montes-Hernández \& Eguiarte (2002) determinaron los niveles de variación genética de los tres taxa del grupo Argyrosperma en Jalisco por medio de loci isoenzimáticos. Encontraron altos niveles de variación genética en estas poblaciones: un porcentaje medio de loci polimórficos para C. moschata de $97 \%$, una heterocigosis esperada $\left(H_{E}\right)$ de 0.416 y un ligero exceso de heterócigos (con respecto a lo que se esperaría si los apareamientos fueran al azar) en las poblaciones, así como una baja pero significativa diferenciación genética total $\left(F_{S T}=0.087\right)$ para los tres taxa y las 15 poblaciones, lo que sugiere flujo genético entre el grupo y alta cercanía genética entre C. moschata y el grupo Argyrosperma. Sus resultados confirmaron los obtenidos por Wilson (1990), quien analizó 46 poblaciones con datos de loci isoenzimáticos para variedades criollas de $C$. moschata y $C$. argyrosperma ssp. argyrosperma (como C. mixta) y poblaciones silvestres de C. argyrosperma ssp. sororia de varias regiones de México.

Más recientemente, Barboza et al. (2012) describieron la diversidad genética de 218 individuos C. moschata de Mesoamérica mediante PCR-SSCP de la región nuclear ITS1-ITS2 y la región de cloroplasto trnL-trnF. Para la región nuclear encontraron 25 haplotipos y en el cloroplasto 24 . Las muestras de México con el marcador nuclear ITS1-ITS2 revelaron valores altos de diversidad genética $\left(H_{E}=0.874\right)$. Respecto al marcador de cloroplasto las muestras de México mostraron un elevado número de haplotipos (12), lo cual es consistente con los datos del marcador nuclear. Además, los valores de variación genética a nivel secuencia fueron los más altos respecto a las muestras de otros países. Los resultados de este estudio apoyan la idea de que la elevada diversidad es una característica de C. moschata.

Sin embargo, la documentación de la diversidad genética de $C$. moschata de México es limitada, por lo que en este momento se 
están estudiando los niveles de diversidad y los grupos genéticos de variedades nativas de la especie en México, comparando la variación genética y sus patrones geográficos, para así inferir su historia evolutiva y las fuerzas evolutivas que han modelado su filogeografía (Hernández-Rosales et al., en preparación). Actualmente se tienen avances en el estudio de la especie a lo largo de todo México usando microsatélites y marcadores mitocondriales (Hernández-Rosales et al., en preparación); este es el primer estudio que evalúa la diversidad y estructura genética de las variedades nativas (razas locales) de C. moschata que se cultivan en el país. Las estimaciones preliminares de variación genética de C. moschata en todo México (Hernández-Rosales et al., en preparación) son similares a las encontradas en otras especies cultivadas del género Cucurbita, y consistentes con las reportadas por Montes-Hernández \& Eguiarte (2002), aún considerando las diferencias metodológicas (isoenzimas vs. microsatélites nucleares), en el tamaño de la muestra y en particular la cobertura geográfica (una región de Jalisco en Montes-Hernández \& Eguiarte (2002) vs. todo el país en el nuevo estudio de Hernández-Rosales et al., en preparación).

El describir los niveles de variación y estructura genética de las variedades criollas de C. moschata no es suficiente. En el futuro, debemos seguir explorando los escenarios que expliquen los patrones para entender cuáles son las condiciones ambientales que los han generado, así mismo integrar el conocimiento del manejo tradicional de esta especie como un factor importante en su diversificación. Para poder conocer la historia evolutiva y del manejo y domesticación de la especie será necesario integrar más muestras de razas locales, que abarquen la distribución de esta especie y así podremos identificar con mayor precisión el área de domesticación e identificar las zonas geográficas de diversificación.

\section{Cucurbita pepo silvestre y cultivada}

Cucurbita pepo (Tabla I) es la especie de calabaza de mayor importancia comercial en el mundo, y por lo mismo la más estudiada hasta el momento. En esta especie se ha detectado una alta variación genética, como lo documentaron recientemente Ruíz-Mondragón (2017) y Castellanos-Morales et al. (en preparación), como parte de un estudio que abarcó a las variedades comerciales más importantes de México y de Estados Unidos, así como a variedades criollas y poblaciones silvestres de México.

Resultados recientes sugieren dos centros de domesticación independientes en Norte América: uno en Tamaulipas, México, y otro en las tierras bajas del Sureste de Estados Unidos (Ruíz-Mondragón, 2017; Castellanos-Morales et al., 2018). Las poblaciones silvestres de Tamaulipas, llamadas C. pepo ssp. fraterna, se encuentran cercanamente relacionadas con las variedades comerciales C. pepo ssp. pepo de México. De hecho, se encontró que estos taxa tienen los mismos haplotipos de cloroplasto (Ruíz-Mondragón, 2017; Castellanos-Morales et al., 2018). Las variedades comerciales de Estados Unidos parecen estar más relacionadas con las formas silvestres que crecen en ese país, ya que comparten haplotipos de cloroplasto, mientras que a nivel núcleo se pueden diferenciar tres subespecies (Ruíz-Mondragón, 2017; Castellanos-Morales et al., 2018).

La diversidad genética a nivel nuclear en C. pepo es mayor que la de los otros taxa domesticados del género mencionados en las secciones previas (Ruíz-Mondragón, 2017; Castellanos-Morales et al., en preparación). Además, las variedades criollas presentan mayor diversidad genética nuclear que el taxa silvestre C.pepo ssp. fraterna, mientras que las variedades mejoradas presentaron menor variación que las criollas. Los bajos niveles de variación de C. pepo ssp. fraterna pueden estar relacionados con su restringida área de distribución. La variación genética moderada en las variedades mejoradas-como Black-beauty zucchini, Spaguetti y Delicata honey boat, generalmente cultivadas en EUA - puede deberse a que en realidad son híbridos (cruzas de variedades relacionadas con la subespecie fraterna con variedades relacionadas con la subespecie ovifera) de líneas homocigóticas con baja diversidad genética (CastellanosMorales et al., en preparación). La alta diversidad genética encontrada en las variedades locales de México sugiere que esta especie tuvo una rápida expansión poblacional después del evento de domesticación (Ruíz-Mondragón, 2017; CastellanosMorales et al., 2018).

Los resultados recientes indican que indudablemente México es un importante centro de diversidad genética para C. pepo ssp. pepo. Los primeros análisis sugieren un alto flujo génico entre las poblaciones cultivadas y, que a diferencia de lo observado en C. moschata y C. argyrsoperma, no hay clara diferenciación genética entre regiones; apoyando la idea de una rápida expansión del cultivo de esta especie (Ruíz-Mondragón, 2017).

\section{Genómica evolutiva en Cucurbita}

Todas las especies de género Cucurbita tienen 20 pares de cromosomas (Whitaker, 1933) y el tamaño de sus genomas es relativamente pequeño, de unos 366 millones de pares de bases (Mpb) a $416 \mathrm{Mpb}$ (Bennett \& Smith, 1976; Šiško et al., 2003), alrededor del doble que en Arabidopsis thaliana (115 a $211 \mathrm{Mpb}$ ) y casi un orden de magnitud menor que el maíz (2, $500 \mathrm{Mbp}$ ) o que el humano (3, $235 \mathrm{Mpb})$.

Se han realizado detallados mapas del genoma - análisis donde se grafica en qué cromosomas se encuentran diferentes marcadores genéticos y se describe la distancia entre ellos en términos de la recombinación, y su orden relativo- con marcadores moleculares para diferentes especies cultivadas del género, como C. moschata (Gustafson et al., 2008), C. maxima (Zhang et al.,2015) y especialmente en C. pepo, donde también se ha estudiado con detalle su transcriptoma (que se obtiene secuenciando su RNA, como se explicó anteriormente) (Zraidi 
et al., 2007; Gong et al., 2008; Blanca et al., 2011; Esteras et al., 2012).

Estos estudios han revelado un alto grado de sintenia entre especies, en otras palabras, que el orden relativo de los genes en los cromosomas está conservado dentro del género Cucurbita, y que el género parece en general conservar la organización de su genoma (Gong et al., 2008; Gustafson et al., 2008; MonteroPau et al., 2017). Estas características hacen posible el estudio comparativo de diversos linajes utilizando herramientas de evolución molecular para entender sus adaptaciones particulares. En esa misma línea, los estudios comparados del transcriptoma de once taxa del género por Montero-Pau et al. (2017), van a ayudar a buscar de manera más eficiente genes relacionados a adaptaciones particulares y eventualmente ser útiles para el mejoramiento genético de las plantas cultivadas.

Dado que el número cromosómico en calabazas es mayor que en otras cucurbitáceas, desde hace muchos años se propuso que el género Cucurbita desciende de una planta poliploide (Weiling, 1959), es decir, que su genoma deriva de una duplicación genómica completa relativamente reciente, aunque actualmente sus cromosomas indican que son diploides (sus cromosomas se han reorganizado, y su cariotipo no muestra cromosomas repetidos). Estudios recientes sobre los genomas de C. pepo, C. moschata, C. maxima y C. argyrosperma apoyan esta idea (Montero-Pau et al., 2017; Sun et al., 2017; Barrera-Redondo et.al., en preparación): sus genomas poseen una mayor cantidad de genes parálogos (genes duplicados en distintas posiciones en el genoma de una especie) que otras cucurbitáceas, y las tasas de transversión (mutaciones donde cambia una base púrica (adenina y guanina) por una pirimídica (citosina y timina)) en familias génicas sugieren un origen paralelo y reciente (hace unos $30 \pm 4$ millones de años) de estos genes parálogos en los genomas de las calabazas. Este origen correspondería a la fecha en la cual se produjo la poliploidia que fue encontrada en los genomas en el género.

Recientemente se ha concluido la secuenciación completa del genoma de la calabaza pipiana C. argyrosperma ssp. argyrosperma (Barrera-Redondo et. al., en preparación). Este va a ser nuestro genoma de referencia, debido a su alta cobertura (cuántas veces fue secuenciada en promedio cada base del DNA de un genoma) y calidad (tiene pocos errores de lectura en promedio), para posteriores estudios. El genoma se obtuvo a partir de dos plataformas de secuenciación masiva: Illumina, que genera muchas lecturas de alta calidad (elevada profundidad de secuenciación) pero cortas, por lo que son más difíciles de ensamblar, y PacBio, que produce lecturas muy largas, pero da poca cobertura (pocas lecturas) y tiene altas tasas de error (de hasta del 10 al 15\%) (Barrera-Redondo et. al., en preparación). Con el genoma ensamblado resultado de las lecturas de las dos plataformas y datos transcriptómicos, se logró identificar un número de genes similares a los obtenidos en proyectos de secuenciación en otras plantas con flores (Barrera-Redondo et. $a l$, en preparación). Esto es importante ya que confirma que el genoma está bien ensamblado y que se van a poder realizar estudios comparativos detallados de evolución molecular.

Por ejemplo, se están analizando las diferencias a nivel genómico, comparando este genoma recién concluído con otros, como es el genoma de su pariente silvestre C. argyrosperma ssp. sororia y el de la otra especie cultivada muy cercana, C. moschata (Barrera-Redondo et. al., en preparación).

Con los genomas ensamblados y los cambios particulares en sitios de su genoma (DNA), llamados SNPs (del inglés Single Nucleotide Polymorphsims) se están identificando y analizando detalladamente regiones del genoma asociadas al síndrome de domesticación, así como otras regiones genómicas asociadas a la respuesta a distintas condiciones climáticas, como se hizo recientemente en el maíz silvestre, el teosinte (Aguirre-Liguori, 2017; Aguirre-Liguori et al., 2017, manuscrito enviado a y b). Los primeros resultados muestran diferencias entre los genomas domesticados y silvestres debidas al proceso de domesticación. Estos genomas servirán también como referencia para realizar análisis de SNPs de secuencias obtenidas por tGBS, una técnica de secuenciación masiva (Ott et al., 2017), que permite analizar miles y a veces millones de SNPs, con los que se pueden realizar análisis poblacionales del proceso evolutivo y de la dinámica de la domesticación a una resolución antes no imaginada (AguirreLiguori et al., 2017; Fustier et al., 2017.

\section{Discusión y Conclusiones}

Las especies domesticadas de Cucurbita distribuidas en México tienen una elevada variación genética en sus poblaciones, similar a la de sus parientes silvestres. Este es un resultado interesante y relevante, ya que en los procesos de domesticación usualmente se pierde mucha variación genética debido a las reducciones poblacionales y a la intensa selección que sucede durante la domesticación (Solbrig \& Solbrig, 1994; Purugganan \& Fuller, 2009; Meyer \& Purugganan, 2013; Gaut, 2015; Gaut et al., 2015). Por otra parte, esta gran diversidad genética dentro y entre las poblaciones de las variedades, subespecies y especies de Cucurbita indudablemente representa un valioso recurso genético para el futuro manejo y mejoramiento de las especies. Dicha diversidad genética es particularmente relevante frente al cambio climático global, ya que posiblemente dentro de nuestros recursos genéticos se encuentran genes adaptados para todo tipo de condiciones climáticas futuras.

Entre las especies domesticadas, los datos hasta el momento indican que $C$. pepo es la que presenta mayor variación genética. En esta especie se observa un gradiente de diferenciación asociado a los dos eventos de domesticación, una en el territorio actual de Tamaulipas, y otra en el Sureste de los Estados Unidos. Aparentemente diversas variedades comerciales que se cultivan en EUA y Europa se originaron de una hibridización entre esos 
dos linajes, mientras que en México tenemos una alta diversidad proveniente de los dos linajes originales. Otro resultado interesante es que en la Península de Yucatán C. argyrosperma representa una poza genética diferenciada del resto de la especie, ya que el Istmo de Tehuantepec es una importante barrera en la diferenciación genética y la evolución de estas especies.

Los estudios sobre los recursos genéticos y la domesticación del género Cucurbita en México están en una primera fase. Se han realizado colectas a lo largo de todo el país, se conoce relativamente bien su distribución y se tienen bancos de germoplasma adecuados, pero mejorables. Aún falta analizarcon cuidado los detalles de estas especies, su evolución, sus tiempos de origen, sus adaptaciones como respuesta a las condiciones y cambios de su ambiente, así como los diferentes aspectos finos de su domesticación. También se han logrado avances en el estudio de los sitios (regiones) del genoma asociados a la domesticación gracias a los estudios del genoma de diferentes especies en el género. Con esta información, en el futuro próximo también se van a poder realizar análisis predictivos de respuesta de la variación genética en escenarios de cambio ambiental en la calabaza .

Así se puede concluir que el género Cucurbita está resultando un modelo útil, para el estudio moderno del proceso de domesticación, cumpliendo los sueños y metas de diversos investigadores y naturalistas desde Charles Darwin, de De Candolle y de Vavilov, el entender bien el papel de la adaptación y de la selección artificial, de la geografía y de la genética en el proceso de domesticación en plantas.

\section{Agradecimientos}

Agradecemos especialmente a los Proyectos CONABIO KE 004, "Diversidad genética de las especies de Cucurbita en México e hibridación entre plantas genéticamente modificadas y especies silvestres de Cucurbita" y CONABIO PE001 "Diversidad genética de las especies de Cucurbita en México. Fase II, Genómica evolutiva y de poblaciones, recursos genéticos y domesticación", ya que sin estos apoyos, el proyecto no existiría.

Además, también queremos agradecer al CONACYT por el Proyecto Problemas Nacionales 247734 otorgado al Dr. Daniel Piñero del Instituto de Ecología, UNAM, quien además ha sido nuestro mentor, amigo y guía en el proyecto. Agradecemos el apoyo y entusiasmo del Dr. José Sarukhán y de la Dra. María Francisca J. Acevedo Gasman de la CONABIO, por todo su respaldo, a la Dra. Laura Espinosa Asuar y a la Sra. Silvia Barrientos, además de a los alumnos que han colaborado en el proyecto, especialmente Paulina Hernández, Daniel Montes, J. Alejandro Luna, Dulce C. Hernández-Rosales, Gustavo García y Gabriel Manuel Rosas. Finalmente, agradecemos a los tres revisores anómimos por su trabajo detallado. Este artículo fue escrito con apoyo del programa PASPA-DGAPA,
UNAM, a Luis E. Eguiarte y Victoria Souza en la University of Minnesota, St. Paul, en los laboratorios de los Drs. Peter Tiffin y Michael Travisano.

\section{RefERENCIAS}

Aguirre-Liguori, J. A. (2017) Genómica de poblaciones del maíz silvestre, el teocintle (Zea mays ssp. parviglumis y Zea mays ssp. mexicana)(Tesis de Doctorado). Instituto de Ecología, Universidad Nacional Aútonoma de México, México, 136 págs.

Aguirre-Liguori, J. A., Aguirre-Planter, E. \& Eguiarte, L. E. (2016). Genetics and ecology of wild and cultivated maize: domestication and introgression. In: Lira, R., Casas, A. \& Blancas, J. (Eds.). Ethnobotany of Mexico: Interactions of People and Plants in Mesoamerica (pp. 403-416). New York: Springer. https://doi. org/10.1007/978-1-4614-6669-7_16

Aguirre-Liguori, J. A., Tenaillon, M. I., Vázquez-Lobo, A., Gaut, B. S., Jaramillo-Correa, J. P., Montes-Hernández, S., Souza, V. \& Eguiarte, L. E. (2017). Connecting genomic patterns of local adaptation and niche suitability in teosintes. Molecular Ecology, 26(16), 4226-4240. https://doi.org/10.1111/mec.14203

Aguirre-Liguori, J. A., Gaut, B. S., Jaramillo-Correa, J. P., Tenaillon, M. I., Montes-Hernández S., García-Oliva F., Hearne, S. \& Eguiarte L. E. (2018). Divergence with gene flow is driven by local adaptation to temperature and soil phosphorus concentration in teosinte subspecies (Zea mays parviglumis and Zea mays mexicana). In prep.

Aguirre-Liguori, J. A., Ramírez-Barahona, S., Tiffin, P. \& Eguiarte, L. E. (2018). Future climate change predicts population extinction by disrupting local adaptation in wild relatives of maize. In prep.

Aguirre Muñoz, A., Golubov, J. \& Mandujan, M.C. (2015). Batallas biológicas en las islas de México ¿estamos ganando la guerra? Oikos, 13, 6-10. http://web.ecologia.unam.mx/oikos3.0/index. $\mathrm{php} /$ todos-los-numeros/articulos-anteriores/124-batallasbiologicas-en-las-islas-de-mexico-estamos-ganando-la-guerra

Allem, A.C. (2000) The terms genetic resource, biological resource, and biodiversity examined. Environmentalist, 20,335-341.https:// doi.org/10.1023/A:1006730000698

Altieri, M. A. (1995) Agroecology: The science of sustainable agriculture. 2nd Edition, Boulder,CO, Westview Press.

Álvarez-Yépiz, \& Martínez-Yrízar (2015). Huracanes, sequías y heladas: eventos climáticos extremos en México. Oikos, 15, 6-11.http://web.ecologia.unam.mx/oikos3.0/index.php/todos-losnumeros/articulos-anteriores/165-eventos-climaticos-extremosen-ecosistemas

Barboza, N., Albertazz, F.J., Sibaja-Cordero, J.A., Mora-Umaña, F., Astorga, C. \& Ramírez, P. (2012). Analysis of genetic diversity of Cucurbita moschata (D.) germplasm accessions from Mesoamerica revealed by PCR SSCP and chloroplast sequence data. Scientia horticulturae, 134, 60-71. https://doi.org/10.1016/j. scienta.2011.10.02

Beja-Pereira, A., Luikart, G., Englan, P.R., Bradley, D.G., Jann, O.C., Bertorell, G., Chamberlain, A.T., Nunes, T.P., Metodiev, S., Ferrand, N. \& Erhardt, G. (2003). Geneculture coevolution between cattle milk protein genes and human lactase genes. Nature Genetics, 35(4), 311-313. https://doi.org/10.1038/ng1263

Bennett, M. D., \& Smith, J. B. (1976). Nuclear DNA Amounts in Angiosperms. Philosophical Transactions of the Royal Society B: 
Biological Sciences, 274(933), 227-274.https://doi.org/10.1098/ rstb.1976.0044

Bennetzen, J., Buckler, E., Chandler, V., Doebley, J., Dorweiler, J., Gaut, B., Freeling, M., Hake, S., Kellogg, E., Poethig, R.S. \& Walbot, V. (2001). Genetic evidence and the origin of maize. Latin American Antiquity, 12(1), 84-86. http://www.jstor.org/stable/971759

Blanca, J., Cañizares, J., Roig, C., Ziarsolo, P., Nuez, F. \& Picó, B., (2011). Transcriptome characterization and high throughput SSRs and SNPs discovery in Cucurbita pepo (Cucurbitaceae). BMC Genomics, 12(1), 104-118. https://doi.org/10.1186/1471-216412-104

Bisognin, D. A. (2002). Origin and evolution of cultivated cucurbits. Ciência Rural, 32(4), 715-723. https://doi.org/10.1590/S010384782002000400028

Castellanos-Morales, G., Paredes, L., GámezN., Hernández-Rosales, H. S., Sánchez de la Vega, G., Barrera-Redondo, J., Aguirre-Planter, E., Vázquez-Lobo, A., Montes-Hernández, S., Lira-Saade, R. \& Eguiarte, L. E. (2018).Historical biogeography and phylogeny of Cucurbita: insights from ancestral area reconstruction and niche evolution. Molecular phylogenetics and evolution, 128, 38-54 https://doi.org/10.1016/j.ympev.2018.07.016

CONABIO(2006). Capital natural y bienestar social. México, Comisión Nacional para el Conocimiento y Uso de la Biodiversidad.

Darwin, C. (1859). On the origin of species by means of natural selection. 1859. London, Murray.

De Candolle, A. (1883). Origine des plantes cultivées (Vol. 43). G. Baillière et cie. https://books.google.com.mx/books?hl=en\&lr= $\& \mathrm{id}=$ vO8HAAAAIAAJ\&oi $=$ fnd $\&$ pg $=$ PA $1 \& \mathrm{dq}=\mathrm{de}+$ Candolle $\&$ ots $=$ YOU02O4wkv\&sig=jqJOqA1m1moQKU19NxexYG517v $\mathrm{Q} \# \mathrm{v}=$ onepage $\& \mathrm{q}=\mathrm{de} \% 20$ Candolle $\& \mathrm{f}=$ false

Dirzo R., Young, H.S., Galetti, M., Ceballos, G., Isaac, N.J. \& Collen, B. (2014). Defaunation in the Anthropocene. Science, 345(6195), 401-406. https:/www.researchgate.net/profile/Mauro Galetti/ publication/264247848 Defaunation in the Anthropocene/links/53f 911111c1a0cf27c365cea9088/Defaunation-in-the-Anthropocene. pdf

Eguiarte, L.E. (1986). Una guía para principiantes a la genética de poblaciones. Ciencias, Número especial 1, 30-39. File:///Users/ luis/Downloads/10896-10641-0-PB.pdf

Eguiarte, L. E., Aguirre-Liguori, J. A., Jardón-Barbolla, L., AguirrePlanter, E. \& Souza, V. (2013). Genómica de poblaciones: nada en Evolución va a tener sentido si no es a la luz de la genómica, y nada en genómica tendrá sentido si no es a la luz de la evolución. TIP. Revista especializada en ciencias químicobiológicas, 16(1), 42-56. http://www.scielo.org.mx/scielo. php?script=sci_arttext\&pid=S1405-888X2013000100005\&lng $=$ es\&nrm $=$ iso

Eguiarte, L.E., Equihua Zamora, C. \& Espinosa-Asuar, L. (2017). La milpa es un espejo de la diversidad biológica y cultural de México. Oikos, 17, 7-9 http://web.ecologia.unam.mx/oikos3.0/ index.php/todos-los-numeros/articulos-anteriores/210-milpaespejo-de-la-diversidad

Escalante,A.E., Jardón-Barbolla, L., Ramírez-Barahona, S. \& Eguiarte, L.E. (2014). The study of biodiversity in the era of massive sequencing. Revista Mexicana de Biodiversidad, 85, 1249-1264. https://doi.org/10.7550/rmb.43498

Esteras, C., Gómez, P., Monforte, A. J., Blanca, J., Vicente-Dolera, N., Roig, C., Nuez, F. \& Pico, B. (2012). High-throughput SNP genotyping in Cucurbita pepo for map construction and quantitative trait loci mapping. BMC Genomics, 13(1), 80. https:// doi.org/10.1186/1471-2164-13-80

FAO (2011). Segundo plan de acción mundial para los recursos fitogenéticos para la alimentación y la agricultura. Comisión de recursos genéticos para la alimentación y la agricultura. Roma, Italia.

Francis, R.C. (2015). Domesticated: evolution in a man-made world. W.E. Norton, New York, USA.

Fustier, M.A., Bandenburg, J.T., Boitard, S., Lapeyronnie, J., Eguiarte, L. E., Vigouroux, Y., Manicacci, D. \& Tenaillon, M. I. (2017) Signatures of local adaptation in lowland and highland teosintes from whole-genome sequencing of pooled samples. Molecular Ecology, 26(10), 2738-2756. https://doi.org/10.1111/mec.14082

Gaut, B.S. (2015). Evolution is an experiment: assessing parallelism in crop domestication and experimental evolution: (Nei Lecture, SMBE 2014, Puerto Rico). Molecular Biology and Evolution, 32(7), 1661-1671. https://doi.org/10.1093/molbev/ msv105

Gaut, B.S., Díez, C.M. \& Morrell, P.L. (2015). Genomics and the contrasting dynamics of annual and perennial domestication. Trends in Genetics, 31(12), 709-719. https://doi. org/10.1016/j.tig.2015.10.002

Gepts, P. (2014). The contribution of genetic and genomic approaches to plant domestication studies. Current Opinion in Plant Biology, 18(1), 51-59. https://doi.org/10.1016/j.pbi.2014.02.001

Gerbault, P., Liebert, A., Itan, Y., Powell, A., Currat, M., Burger, J., Swallow, D.M. \& Thomas, M.G. (2011). Evolution of lactase persistence: an example of human niche construction. Philosophical Transactions of the Royal Society B: Biological Sciences, 366(1566), 863-877. https://doi.org/10.1098/ rstb.2010.0268

Gliessmann, S. R. (1983). Allelopathic interactions in crop-weed mixtures: applications for weed management. Journal Chemical Ecology, 9, 991. https://doi.org/10.1007/BF00982206

Gliessmann, S. R. (1990) The ecology and management of traditional farming systems. In: M.A. Altieri and S. B. Hecht (eds.). Agroecology, and Small Farm Development. BocaRaton, Florida, CRC Press,

Gong, L., Stift, G., Kofler, R., Pachner, M. \& Lelley, T. (2008). Microsatellites for the genus Cucurbita and an SSR-based genetic linkage map of Cucurbita pepo L. Theoretical and Applied Genetics, 117(1), 37-48. https://doi.org/10.1007/s00122-0080750-2

Guerra-García,A., Suárez-Antillano, M., Mastretta-Yanes,A., DelgadoSalinas, A. \& Piñero, D. (2017). Domestication genomics of the open-pollinated scarlet runner bean (Phaseoulus coccineus L.). Frontiers in Plant Science, 8, 1891. http://doi.org/10.3389/ fpls.2017.01891

Gustafson, P., Gong, L., Pachner, M., Kalai, K. \& Lelley, T. (2008). SSR-based genetic linkage map of Cucurbita moschata and its synteny with Cucurbita pepo. Genome, 51(11), 878-887. https:// doi.org/10.1139/G08-072

Hancock, J. F. (2005). Contributions of domesticated plant studies to our understanding of plant evolution. Annals of Botany, 96(6), 953-963. https://doi.org/10.1093/aob/mci259

Hufford, M.B., Xu, X., van Heerwaarden, J., Pyhäjärvi, T., Chia, J.-M., Cartwright, R. A., Elshire, R. J., Glaubitz, J. C., Guill, K. E., Kaeppler, S. M., Lai, J., Morrell, P. L., Shannon, L. M., Song, C., Springer, N. M., Swanson-Wagner, R. A., Tiffin, P., 
Wang, J., Zhang, G., Doebley, J., McMullen, M. D., Ware, D., Buckler, E. S., Yang, S. \& Ross-Ibarra, J. (2012a). Comparative population genomics of maize domestication and improvement. Nature Genetics, 44(7), 808-811.https://doi.org/10.1038/ng.2309

Hufford, M.B., Martínez-Meyer, E., Gaut, B.S., Eguiarte, L.E. \& Tenaillon, M.I. (2012b). Inferences from the historical distribution of wild and domesticated maize provide ecological and evolutionary insight. PLoS One, 7(11), 47659. https//doi. org/10.1371/journal.pone.0047659

Hurd, P. D., Linsley, E. G. \& Whitaker, T. W. (1971). Squash and gourd bees (Peponapis, Xenoglossa) and the origin of the cultivated Cucurbita. Evolution, 25, 218-234. https://doi. org/10.1111/j.1558-5646.1971.tb01874.x

Ingram, C.J.E., Mulcare, C.A., Itan, Y., Thomas, M.G. \& Swallow, D.M. (2009). Lactose digestion and the evolutionary genetics of lactase persistence. Human Genetics, 124(6), 579-591. https:// doi.org/10.1007/s00439-008-0593-6

Jardón-Barbolla, L. (2015). Orígenes y diversidad a la mitad de las montañas: Nikolai Vavílov, México y las plantas domesticadas. Oikos, 14, 6-10. http://web.ecologia.unam.mx/oikos3.0/index. $\mathrm{php} /$ oikos-historico/numeros-anteriores/141-origenes-ydiversidad-a-la-mitad-de-las-montanas-nikolai-vavilov-mexicoy-las-plantas-domesticadas.

Jiao, Y., Zhao, H., Ren, L., Song, W., Zeng, B., Guo, J., Wang, B., Liu, Z., Chen, J., Li, W., Zhang, M., Xie, S. \& Lai, J. (2012). Genome-wide genetic changes during modern breeding of maize. Nature Genetics, 44(7), 812-815. https: //doi.org/10.1038/ng.2312Kates, H.R., Soltis, P.S. \& Soltis, D.E. (2017). Evolutionary and domestication history of Cucurbita (pumpkin and squash) species inferred from 44 nuclear loci. Molecular Phylogenetics and Evolution, 111, 98-109. https://doi.org/10.1016/j.ympev.2017.03.002

Kato, T.A., Mapes, C., Mera, L.M., Serratos, J.A. \& Bye, R.A. (2009). Origen y diversificación del maíz: una revisión analítica. México, D.F.: Universidad Nacional Autónoma de México, Comisión Nacional para el Conocimiento y Uso de la Biodiversidad.

Kistler, L., Newsom, L. A., Ryan, T. M., Clarke, A. C., Smith, B. D. \& Perry, G. H. (2015). Gourds and squashes (Cucurbita spp.) adapted to megafaunal extinction and ecological anachronism through domestication. Proceedings of the National Academy of Sciences, 112(49), 15107-15112.https://doi.org/10.1073/pnas.1516109112

Koenig, D., Jimenez-Gomez, J. M., Kimura, S., Fulop, D., Chitwood, D. H., Headland, L. R., Kumar, R., Covington, M. F., Devisetty, U. K., Tat, A. V., Tohge, T., Bolger, A., Schneeberger, K., Ossowski, S., Lanz, C., Xiong, G., Taylor-Teeples, M., Brady, S. M., Pauly, M., Weigel, D., Usadel, B., Fernie, A. R., Peng, J., Sinha, N. R. \& Maloof, J.N. (2013). Comparative transcriptomics reveals patterns of selection in domesticated and wild tomato. Proceedings of the National Academy of Sciences, 110(28), E2655-E2662. https:// doi.org/10.1073/pnas.1309606110

Laland, K.N., Odling-Smee, J. \& Myles, S. (2010). How culture shaped the human genome: bringing genetics and the human sciences together. Nature Reviews Genetics, 11(2), 137-148. http://doi:10.1038/nrg2734

Lam, H.-M., Xu, X., Liu, X., Chen, W., Yang, G., Wong, F.-L., Li, M-W., He, W., Qin, N., Wang, B., Li, J., Jian, M., Wang, J., Shao, G., Wang, J., Sun, S. S-M. \& Zhang, G. (2010). Resequencing of 31 wild and cultivated soybean genomes identifies patterns of genetic diversity and selection. Nature Genetics, 42(12), 1053-1059.

Li, J., Jian, M., Wang, J., Shao, G., Wang, J., Sun, S. S-M. \& Zhang,
G. (2010). Resequencing of 31 wild and cultivated soybean genomes identifies patterns of genetic diversity and selection. Nature Genetics, 42(12), 1053-1059.

Li, Y., Zhao, S., Ma, J., Li, D., Yan, L., Li, J., Qi, X., Guo, X., Zhang, L., He, W., Chang, R., Liang, Q., Guo, Y., Ye, C., Wang, X., Tao, Y., Guan, R., Wang, J., Liu, Y., Jin, L., Zhang, X., Liu, Z., Zhang, L., Chen, J., Wang, K., Nielsen, R., Li, R., Chen, P., Li, W., Reif, J. C., Purugganan, M., Wang, J., Zhang, M., Wang, J. \& Qiu, L-J. (2013). Molecular footprints of domestication and improvement in soybean revealed by whole genome re-sequencing. $B M C$ Genomics, 14(1), 579. https://doi.org/10.1186/1471-2164-14-579

Lin, T., Zhu, G., Zhang, J., Xu, X., Yu, Q., Zheng, Z., Zhang, Z., Lun, Y., Li, S., Wang, X., Huang, Z., Li, J., Zhang, C., Wang, T., Zhang, Y., Wang, A., Zhang, Y., Lin, K., Li, C., Xiong, G., Xue, Y., Mazzucato, A., Causse, M., Fei, Z., Giovannoni, J. J., Chetelat, R. T., Zamir, D., Städler, T., Li, J., Ye, Z., Du, Y. \& Huang, S. (2014). Genomic analyses provide insights into the history of tomato breeding. Nature Genetics, 46(11), 1220-1226. https:// doi.org/10.1038/ng.3117

Lira-Saade, R. (1995). Estudios taxonómicos y ecogeográficos de las Cucurbitaceae latinoamericanas de importancia económica. Systematic and ecogeographic studies on crop genepools. 9. International Plant Genetic Resources Institute, Rome.

Lira, R., Andres, T.C. \& Monro, A.K. (2009a). Cucurbita L. In Davids, G., Sousa, M.S., Knapp, S. \& Chiang, F. (eds.). Flora Mesoamericana Vol.4 (pp.9-13). Cucurbitaceae a Polemoniaceae. Missouri: Botanical Garden Press.

Lira, R., Eguiarte, L. E. \& Montes-Hernández, S. (2009b). Proyecto Recopilación y análisis de la información existente de las especies de los géneros Cucurbita y Sechium que crecen y / o se cultivan en México. México, D.F.: CONABIO, 107p.

Lira, R., Eguiarte, L., Montes, S., Zizumbo-Villarreal, D., Marín, P.C.G. \& Quesada, M. (2016). Homo sapiens-Cucurbita interaction in Mesoamerica: Domestication, Dissemination, and Diversification. In Lira, R., Casas, A. \& Blancas, J. (eds.). Ethnobotany of Mexico (pp. 389-401). Ethnobiology. New York: Springer. https://doi. org/10.1007/978-1-4614-6669-7_15

Lozada-Aranda, M., Rojas Barrera, I., Mastretta Yanes, A., PonceMendoza, A., Burgeff, C., Orjuela-R, M.A. \& Oliveros, O. (2017). Las milpas de México. Oikos, 17, 10-12. http://goo.gl/fsFQxq

Mangelsdorf, P.C. (1974). Corn. Its origin, evolution and improvement. Cambridge, Massachusetts: Belknap Press of Harvard University Press.

Medina, F.M. \& Nogales, M. (2009). A review on the impacts of feral cats (Felis silvestris catus) in the Canary Islands: implications for the conservation of its endangered fauna. Biodiversity and Conservation, 18(4), 829-846. https://doi.org/10.1007/s10531008-9503-4

Meyer, R. S. \& Purugganan, M. D. (2013). Evolution of crop species: genetics of domestication and diversification. Nature Reviews. Genetics, 14, 840-852. https://doi.org/10.1038/nrg3605

Montero-Pau, J., Blanca, J., Bombarely, A., Ziarsolo, P., Esteras, C., Martí-Gómez, C., Ferriol, M., Gómez, P., Jamilena, M., Mueller, L., Picó, B. \& Cañizares, J. (2017). De novo assembly of the zucchini genome reveals a whole genome duplication associated with the origin of the Cucurbita genus. Plant Biotechnology J., 12(10), 3218-3221. https://doi.org/10.1111/pbi.12860

Montes- Hernández, S. (2002). Flujo génico en calabaza (Cucurbita spp.) dentro del sistema milpa en la parte central de México 
(Tesis de Doctorado). Facultad de Ciencias, Universidad Nacional Autónoma de México, México. 107 págs.

Montes-Hernández, S. \& Eguiarte, L. E. (2002). Genetic structure and indirect estimates of gene flow in three taxa of Cucurbita (Cucurbitaceae) in western Mexico. Am. J. Bot., 89, 1156- 1163. https://doi.org/10.3732/ajb.89.7.1156

Montes-Hernández, S., Merrick, L.C. \& Eguiarte, L.E. (2005) Maintenance of squash (Cucurbita spp.) landrace diversity by farmers' activities in Mexico. Genetic Resource and Crop Evolution, 52(6), 697-707. http://doi.org/10.1017/s10722-0036018-4

Moreno-Letelier, A., Liguori, J.A., Tenaillon, M.I., Piñero, D., Gaut, B.S., Lobo,A.V.\& Eguiarte, L.E. (2018). Was maize domesticated in the Balsas Basin? Complex patterns of genetic divergence, gene flow and ancestral introgressions among Zea subspecies suggest an alternative scenario. bioRxiv, p. 239707. DOI: https:// doi.org/10.1101/239707

Nee, M. (1990). The domestication of Cucurbita (Cucurbitaceae). Economic Botany, 44(Suppl 3), 56-68. https://doi.org/10.1007/ BF02860475

Ott, A., Liu, S., Schnable, J.C., Yeh, C.T., Wang, K.S. \& Schnable, P.S. (2017). tGBS $\AA$ genotyping-by-sequencing enables reliable genotyping of heterozygous loci. Nucleic Acids Research, 45(21), e178. https://doi.org/10.1093/nar/gkx853

Paredes Torres, L. M. (2016). Filogenia molecular del género Cucurbita L. (Cucurbitaceae) usando secuencias de cloroplasto (Tesis de Licenciatura). FES Iztacala, Universidad Nacional Autónoma de México. México. 96 págs.

Paris, H. S. (2016). Genetic Resources of Pumpkins and Squash, Cucurbita spp. In Grumet R., Katzir, N., GarciaMas, J. (eds.). Genetics and Genomics of Cucurbitaceae (pp. 111-154). Plant Genetics and Genomics: Crops and Models, vol 20. (pp. 1-26) Switzerland: Springer Cham. https://doi. org/10.1007/7397 2016 3

Piñero, D. (1987). De las bacterias al hombre: la evolución. La Ciencia desde México. Fondo de Cultura Económica, México. http:// bibliotecadigital.ilce.edu.mx/sites/ciencia/volumen1/ciencia2/25/ $\mathrm{htm} /$ bacterias.htm

Purugganan, M. D. \& Fuller, D. Q. (2009). The nature of selection during plant domestication. Nature, 457, 843-848. http://dx.doi. org/10.1038/nature07895

Qi, J., Liu, X., Shen, D., Miao, H., Xie, B., Li, X., Zeng, P., Wang, S., Shang, Y., Gu, X., Du, Y., Li, Y., Lin, T., Yuan, J., Yang, X., Chen, J., Chen, H., Xiong, X., Huang, K., Fei, Z., Mao, L., Tian, L., Städler, T., Renner, S. S., Kamoun, S., Lucas, W. J., Zhang, Z. \& Huang, S. (2013). A genomic variation map provides insights into the genetic basis of cucumber domestication and diversity. Nature Genetics, 45(12), 1510-1515. https://doi.org/10.1038/ng.2801

Qin, C., Yu, C., Shen, Y., Fang, X., Chen, L., Min, J., Wu, Z., Mao, L., Wu, H., Ling-Hu, C., Zhou, H., Lin, H., González-Morales, S., Trejo-Saavedra, D. L., Tian, H., Tang, X., Zhao, M., Huang, Z., Zhou, A., Yao, X., Cui, J., Li, W., Cheng, J., Zhao, S., Xu, M., Luo, Y., Yang, Y., Chen, Z., Feng, Y., Niu, Y., Bi, S., Yang, X., Li, W., Cai, H., Luo, X., Montes-Hernández, S., Leyva-González, M. A., Xiong, Z., He, X., Bai, L., Tan, S., Tang, X., Liu, D., Liu, J., Zhang, S., Chen, M., Zhang, L., Zhang, L., Zhang, Y., Liao, W., Zhang, Y., Wang, M., Lv, X., Wen, B., Liu, H., Luan, H., Zhang, Y., Yang, S., Wang, X., Xu, J., Li, X.,Li, S., Wang, J., Palloix, A., Bosland, P. W., Li, Y., Krogh, A., Rivera-Bustamante, R. F., Herrera-Estrella,
L., Yin, Y., Yu, J., Hu, K. \& Zhang, Z. (2014). Whole-genome sequencing of cultivated and wild peppers provides insights into Capsicum domestication and specialization. Proceedings of the National Academy of Sciences, 111(14), 5135-5140. https://doi. org/10.1073/pnas.1400975111

Romay, M. C., Millard, M. J., Glaubitz, J. C., Peiffer, J. a, Swarts, K. L., Casstevens, T. M. Elshire, R. J.,Acharya, C. B.,Mitchell, S. E., Flint-Garcia, S. A., McMullen, M. D., Holland, J. B., Buckler, E. S. \& Gardner, C. A. (2013). Comprehensive genotyping of the USA national maize inbred seed bank. Genome Biology, 14(6), R55. https://doi.org/10.1186/gb-2013-14-6-r55

Ruiz Mondragón, K. Y. (2017) Filogeografía y diversidad genética en Cucurbita pepo L. 1753 en México (Tesis de Licenciatura). Facultad de Ciencias, Universidad Nacional Autónoma de México, México. 92 págs

Sanjur, O. I., Piperno, D. R., Andres, T. C. \& Wessel-Beaver, L. (2002). Phylogenetic relationships among domesticated and wild species of Cucurbita (Cucurbitaceae) inferred from a mitochondrial gene: Implications for crop plant evolution and areas of origin. Proceedings of the National Academy of Sciences, 99(1), 535-540. https://doi.org/10.1073/pnas.012577299

Sánchez de la Vega, G. (2017) De la cueva a la mesa, y ahora al laboratorio genómico: la diversidad de calabazas de México. Oikos, 17, 11-17. https://goo.gl/SDcfWq

Sánchez de la Vega, G., Castellanos-Morales, G., Gámez, N., Hernández-Rosales, H. S., Vázquez-Lobo, A., Aguirre-Planter, E., Montes-Hernández, S., Lira, R. \& Eguiarte, L.E. (2018) Genetic resources in the "calabaza pipiana" pumpkin (Cucurbita argyrosperma) in Mexico: Genetic diversity, genetic differentiation and distribution models. Frontiers in Plant Science, 6, 400. http:// doi.org/10.3389/fpls. 2018.00400

Schaefer, H., Heibl, C. \& Renner, S.S. (2009). Gourds afloat: a dated phylogeny reveals an Asian origin of the gourd family (Cucurbitaceae) and numerous oversea dispersal events. Proceedings of the Royal Society ofLondon B: Biological Sciences, 276(1658), 843-851. https://doi.org/10.1098/rspb.2008.1447

Schmutz, J., McClean, P. E., Mamidi, S., Wu, G. A., Cannon, S. B., Grimwood, J., Jenkins, J., Shu, S., Song, O., Chavarro, C., TorresTorres, M., Geffroy, V., Moghaddam, S.M., Gao, D., Abernathy, B., Barry, K., Blair, M., Brick, M.A., Chovatia, M., Gepts, P., Goodstein, D. M., Gonzales, M., Hellsten, U., Hyten, D.L., Jia, G., Kelly, J.D., Kudrna, D., Lee, R., Richard, M.M.S., Miklas, P.N., Osorno, J.M., Rodrigues, J., Thareau, V., Urrea, C.A., Wang, M., Yu, Y., Zhang, M., Wing, R.A., Cregan, P.B., Rokhsar, D.S. \& Jackson, S. A. (2014). A reference genome for common bean and genome-wide analysis of dual domestications. Nature Genetics, 46(7), 707-713. https://doi.org/10.1038/ng.3008

Shang, Y., Ma, Y., Zhou, Y., Zhang, H., Duan, L., Chen, H., Zeng, J., Zhou, Q., Wang, S., Gu, W., Liu, M., Ren, J., Gu, X., Zhang, S., Wang, Y., Yasukawa, K., Bouwmeester, H. J., Qi, X., Zhang, Z., Lucas, W. J. \& Huang, S. (2014). Biosynthesis, regulation, and domestication of bitterness in cucumber. Science, 346(6213), 1084-1088. https://doi.org/10.1126/science. 1259215

Simoons, F.J. (1970). Primary adult lactose intolerance and the milking habit: A problem in biologic and cultural interrelations. Dig. Dis. Sci., 15(8), 695-710.

Šiško, M., Ivančič, A. \& Bohanec, B. (2003). Genome size analysis in the genus Cucurbita and its use for determination of interspecific hybrids obtained using the embryorescue technique. Plant Science, 
165(3), 663-669. https://doi.org/10.1126/science.1259215

Solbrig, O.T., \& Sobrig, D.J. (1994). So shall you reap: Farming and crops in human affairs. Island Press, Washington, D.C., USA.

Sun, H., Wu, S., Zhang, G., Jiao, C., Guo, S., Ren, Y., Zhang, J.,Zhang, H., Gong, G., Jia, Z., Zhang, F., Tian, J., Lucas, W. J., Doyle, J. J., Li, H., Fei, Z. \& Xu, Y. (2017). Karyotype Stability and Unbiased Fractionation in the Paleo-Allotetraploid Cucurbita Genomes. Molecular Plant, 10(10), 1293-1306. https://doi.org/10.1016/j. molp.2017.09.003

Villanueva, C. V. (2007). Calabazas cultivadas. Identificación de especies, caracterización y descripción varietal. Chapingo, Estado de México: Universidad Autónoma Chapingo.

Weiling, F. (1959). Genomanalytische Untersuchungen bei Kürbis (Cucurbita L.). Der Züchter, 29(4), 161-179.

Wilson, H. (1990). Gene Flow in Squash Species. BioScience, 40 (6), 449-455. https://doi.org/10.2307/1311392

Whitaker, T. W. (1933). Cytological and Phylogenetic Studies in the Cucurbitaceae. Botanical Gazette, 94(4), 780-790. https://doi. org $/ 10.1086 / 334347$

Whitaker, T. W. (1981). Archeological cucurbits. Economic Botany, 35(4), 460-466. https://doi.org/10.1007/BF02858596

Whitaker, T.W. \& Davis, G.N. (1962). Cucurbits: Botany, Cultivation, and Utilization. NewYork: Interscience. Publishers.

Xu, X., Liu, X., Ge, S., Jensen, J. D., Hu, F., Li, X., Dong, Y., Gutenkunst, R. N., Fang, L., Huang, L., Li, J., He, W., Zhang, G., Zheng, X., Zhang, F., Li, Y., Yu, C., Kristiansen, K., Zhang, X., Wang, J., Wright, M., McCouch, S., Nielsen, R., Wang, J. \& Wang, W. (2011). Resequencing 50 accessions of cultivated and wild rice yields markers for identifying agronomically important genes. Nature Biotechnology, 30(1), 105-111.https://doi.org/10.1038/nbt.2050
Zeder, M. A. (2015). Core questions in domestication research. Proceedings of the National Academy of Sciences, 112(11), 3191-3198. https://doi.org/10.1073/pnas.1501711112

Zhang, G., Ren, Y., Sun, H., Guo, S., Zhang, F., Zhang, J., Zhang, H., Jia, Z., Fei, Z., Xu, Y. \& Li, H. (2015). A high-density genetic map for anchoring genome sequences and identifying QTLs associated with dwarf vine in pumpkin (Cucurbita maxima Duch.). BMC Genomics, 16(1), 1101. https://doi.org/10.1186/ s12864-015-2312-8

Zheng, Y. H., Alverson, A. J., Wang, Q. F. \& Palmer, J. D. (2013). Chloroplast phylogeny of Cucurbita: Evolution of the domesticated and wild species. Journal of Systematics and Evolution, 51(3), 326-334. https://doi.org/10.1111/jse.12006

Zizumbo-Villarreal, D. \& Terán, S, (1985). Las semillas de la cultura. Los agrosistemas tradicionales una alternativa de desarrollo. Boletín de la Escuela de Ciencias Antropológicas de la Universidad Autónoma de Yucatán, 72, 3-18.

Zizumbo-Villarreal, D., Colunga-GarcíaMarín, P., May-Pat, F, Martínez-Castillo, J. \& Mijangos-Cortés, J.O. (2010). Recursos fito-genéticos para la alimentación y la agricultura. In DuránGarcía R, Méndez-González M(eds.) Biodiversidady Desarrollo Humano en Yucatán. Mérida, Yucatán: CICY, PPD-FMAM, CONABIO, SEDUMA.

Zizumbo-Villarreal, D. \& Colunga-GarcíaMarín, P. (2010). Origin of agriculture and plant domestication in West Mesoamerica. Genetic Resources and Crop Evolution, 57(6), 813-825. https:// doi.org/10.1007/s10722-009-9521-4

Zraidi, A., Stift, G., Pachner, M., Shojaeiyan, A., Gong, L. \& Lelley, T. (2007).Aconsensus map for Cucurbita pepo. Molecular Breeding, 20(4), 375-388. https://doi.org/10.1007/s11032-007-9098-6 